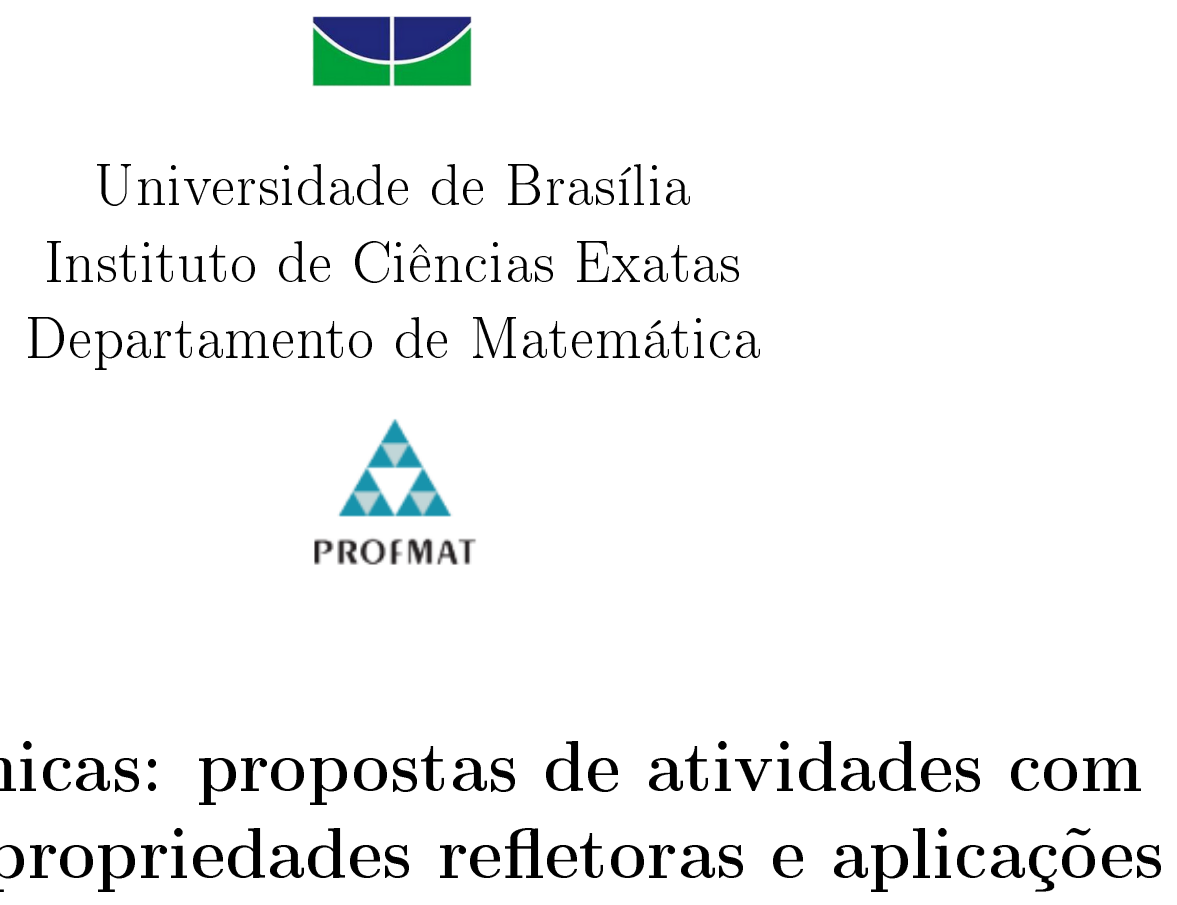

Seções Cônicas: propostas de atividades com ênfase nas propriedades refletoras e aplicações

por

Moacir Carvalho Alves Júnior

Brasília 


\section{Seções Cônicas: propostas de atividades com ênfase nas propriedades refletoras e aplicações}

por

\section{Moacir Carvalho Alves Júnior *}

Dissertação apresentada ao Departamento de Matemática da Universidade de Brasilia, como parte dos requisitos do "Programa" de Mestrado Profissional em Matemática em Rede Nacional - PROFMAT, para obtenção do grau de

\section{MESTRE}

Brasília, 25 de Junho de 2015

Comissão Examinadora:

Prof. Dr. Helder de Carvalho Matos - MAT/UnB - (Orientador)

Prof. Dr. Vinicius de Carvalho Rispoli - FGA/UnB

Prof. Dr. Rui Seimetz - MAT/UnB

${ }^{*} \mathrm{O}$ autor foi bolsista do CAPES durante a elaboração deste trabalho. 
Dedico este trabalho à minha esposa Alessandra, às minhas filhas Letícia e Larissa, aos meus irmãos Kléber, Fernando, Adriana e Patrícia e aos meus pais Moacir e Divina. 


\section{Agradecimentos}

É muito difícil fazer agradecimentos em momentos tão importantes em nossas vidas como este, pois sempre deixamos de citar várias pessoas que de uma forma ou de outra foram extremamente importantes para nossa caminhada. Em razão disso, começo agradecendo a todos aqueles que tiveram sua parcela de colaboração em meu trabalho.

Em especial, agradeço à minha família que, de uma forma incondicional, me proporcionou todas as condições de trabalhar.

Agradeço à minha esposa Alessandra que sempre me apoiou e foi compreensiva em minhas ausências. Meu caminho teria sido muito mais difícl sem seu apoio.

Agradeço também às minhas filhas Letícia e Larissa que me incentivaram e acreditaram em mim. Elas sempre acham que vou conseguir tirar tudo de letra. Elas levantam minha autoestima me deixando mais forte para encarar os desafios.

Agradeço ainda à minha mãe Divina que, sempre com aquele jeito que só mãe tem, me falava pra não desistir. Parece até que percebia os exatos momentos que batia o desespero, me dava aquele colo e me falava as palavras que precisava ouvir.

Agradeço aos meus irmãos Fernando, Adriana e Patrícia, pelo amor e pelos exemplos de conduta que sempre me deram; e um agradecimento em especial ao meu irmão mais velho Kléber que sem dúvida alguma, é um dos grandes responsáveis por esta conquista, servindo de exemplo e inspiração para mim e para meus demais irmãos.

Não posso deixar de citar também minha sogra Neuza por todas as suas orações. Minha segunda mãe.

Evidentemente não poderia deixar de agradecer à minha turma e a todos os professores do Profmat que com extrema competência compartilharam comigo um pouco de seus riquíssimos conhecimentos e em especial ao meu professor orientador Helder Matos que me ajudou bastante com sua grande experiência.

Por fim quero agradecer ao meu pai Moacir, in memorian, que sempre acreditou e colocou a mim e a meus irmãos entre os melhores filhos do mundo, se enchendo de orgulho por cada vitória que alcançávamos. Isso foi fundamental para que também acreditássemos em nós.

Agradeço à CAPES pelo apoio financeiro à este trabalho.

Este trabalho é um pouco do que posso dar em oferecimento pelo apoio incondicional. 
"A Matemática não é algo que diz respeito a números, mas sim à vida. Ela é algo que nasce do mundo em que vivemos. Lida com ideias. E, longe de ser aborrecida e estéril, como muitas vezes é retratada, ela é cheia de criatividade. (Delvin, 2005, p.98)" 


\section{Resumo}

Neste trabalho desenvolvo uma proposta de abordagem para o assunto seções cônicas. Inicialmente faço um resumo do seu desenvolvimento histórico, citando obras e estudiosos de grande importância para o tema. Em seguida, apresento fundamentações teóricas dos conceitos relacionados às cônicas sob pontos de vista distintos. Faço ainda, uma explanação sobre os fatores que motivaram o desenvolvimento dessa teoria, dando uma ênfase às propriedades refletoras das curvas cônicas e algumas aplicações desses conceitos. Finalmente, apresento propostas de atividades que podem ser trabalhadas por professores do ensino médio, com seus alunos.

Palavras-chaves: Seções cônicas; propriedades refletoras; aplicações. 


\section{Abstract}

In this work I develop a proposed approach to the subject conic sections. Initially, making a summary of its historical development, citing works and scholars of great importance for the theme. Then I present theoretical foundations of the concepts related to the conics under different points of view. I still make an explanation of the factors that motivated the development of this theory, giving an emphasis to the reflective properties of conic curves and some applications of these concepts. Finally, I present proposals for activities that can be worked by high school teachers with their students.

Key-words: conic sections; reflective properties; applications. 


\section{Sumário}

Introdução 1

1 Uma abordagem histórica para o estudo das cônicas 3

2 Fundamentação Teórica 6

2.1 Abordagem Geométrica . . . . . . . . . . . . . . 6

2.2 Abordagem Analítica . . . . . . . . . . . . . . . . 9

2.2 .1 Elipse .............................. 9

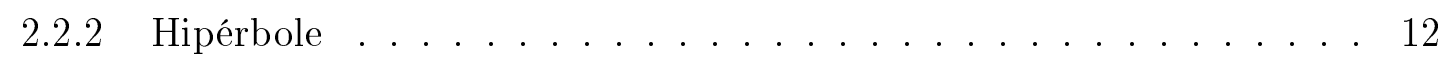

2.2 .3 Parábola . . . . . . . . . . . . . . . . . 13

2.3 Abordagem por meio de coordenadas polares . . . . . . . . . . . . . . 15

2.3.1 Coordenadas Polares . . . . . . . . . . . . . . . 15

2.3.2 Equação da Elipse em cordenadas Polares . . . . . . . . . . . . 18

2.3.3 Equação da Hipérbole em cordenadas Polares . . . . . . . . . . . . 19

2.3.4 Equação da Parábola em cordenadas Polares . . . . . . . . . . . . . 21

3 Fatores que motivaram o estudo e o desenvolvimento da teoria das cônicas $\quad 24$

3.1 Propriedades refletoras da elipse . . . . . . . . . . . . . . 25

3.2 Propriedades refletoras da parábola . . . . . . . . . . . . . . . 28

3.3 Propriedades refletoras da hipérbole . . . . . . . . . . . . . . 35

4 Propostas de atividade para se trabalhar as curvas elipses, hipérboles e parábolas no ensino médio $\quad 39$

4.1 Atividade de manipulação de materiais articulados . . . . . . . . . . . . . 39

4.1.1 Parabológrafo: Instrumento articulado para traçar parábolas . . . . 40 
4.1.2 Elipsógrafo: Instrumento articulado para traçar elipses . . . . . . . 43

4.1.3 Hiperbológrafo: Instrumento articulado para traçar hipérboles . . . 47

4.2 Atividade de utilização de sombras para observações das seções cônicas . 50

4.3 Atividade com cortes em cones de isopor para visualizações das seções cônicas 57

4.4 Atividade de construção da mesa de sinuca elíptica . . . . . . . . . . . 60 


\section{Introdução}

É bastante normal e razoável acreditar que quando um professor vai iniciar um assunto novo com sua turma vem a ele aquelas famosas perguntas: Como devo fazer para introduzir este conceito? Como fazer para que os alunos sintam interesse em estudar o tema? Ensinar matemática não é uma tarefa muito fácil. A Matemática tem a fama de ser uma matéria difícil e que poucas pessoas gostam. Muitas acham que estudam algo que não tem sentido algum, que não serve para nada em suas vidas. Cabe a nós professores tentar desmistificar um pouco essa visão. Ao se fazer essas perguntas entendo que dentre outras preocupações, o professor deve ter também o cuidado de tentar fazer com que o alunos percebam a importância de cada assunto abordado. Deve trabalhar para que o assunto faça sentido.

O que se percebe é que os estudantes acabam passando pelo ensino médio e saem sem ter a ideia de onde poderão utilizar o que foi estudado.

Neste trabalho discute-se uma abordagem do assunto seções cônicas usando perspectiva histórica, destacando seu desenvolvimento e os fatores motivadores disso, demonstrar as propriedades reflexivas das cônicas e suas aplicações em diversas áreas, sua importância no desenvolvimento de tecnologias e finalmente apresentar propostas de atividades a serem desenvolvidas por professores com seus alunos do ensino médio.

Não tenho aqui a pretensão de dizer como se deve trabalhar este assunto; quero sim, apresentar propostas de aulas que possam ser utilizadas por professores no intuito de dar uma abordagem mais prática e ilustrativa. Tenho a intensão de contribuir com sugestões para elaborações de planos de aulas.

Será que apresentar o conteúdo Cônicas mostrando quais foram as necessidades da humanidade que motivaram a evolução dessa teoria e como foram utilizadas suas propriedades no desenvolvimento de novas tecnologias não proporcionaria um aprendizado mais significativo para o aluno do Ensino Médio?

Apresentar aos alunos quais foram as necessidades de épocas passadas e que motivaram à busca de uma nova teoria que pudesse ajudar o homem a solucionar problemas que 
até então não tinham soluções pode ser uma forma bastante interessante para atrair a curiosidade e interesse de nossos alunos para o estudo da Matemática. Fazer com que o estudante entenda o porquê de se estudar cada assunto e saber fazer uso dele e inseri-lo no contexto histórico pode tornar a aprendizagem mais significativa.

Segundo Bento de Jesus Caraça, referência [4]

A ciência pode ser encarada sob dois aspectos diferentes. Ou se olha para ela tal como vem exposta nos livros de ensino, como coisa criada, e o aspecto é o de um todo harmonioso, onde os capítulos se encadeiam em ordem, sem contradições. Ou se procura acompanhá-la no seu desenvolvimento progressivo, assistir à maneira como foi sendo elaborada, e o aspecto é totalmente diferente; descobrem-se hesitações, dúvidas, contradições, que só um longo trabalho de reflexão e apuramento consegue eliminar, para que logo surjam outras hesitações, outras dúvidas, outras contradições.

Descobre-se ainda qualquer coisa mais importante e mais interessante: - no primeiro aspecto, a Ciência parece bastar-se a si própria, a formação dos conceitos e das teorias parece obedecer só a necessidades interiores; no segundo, pelo contrário, vê-se toda a influência que o ambiente da vida social exerce sobre a criação da Ciência. (Caraça, 1970, p. XII)

Todo desenvolvimento da Matemática se deu e ainda se dá mediante às necessidades do ser humano em resolver problemas que podem ser novos, mas também podem ser antigos. Existem vários tipos de problemas que motivaram o desenvolvimento matemático, a necessidade de se fazer contagens, as relações de comércio, a utilização do espaço e de formas, mas em muitos casos, apenas pelo simples fato de se tentar estabelecer relações. No caso das cônicas não foi diferente. Inicialmente, os pensadores estudavam as cônicas apenas como curiosidades sobre essas curvas e suas belezas. Porém, com o avanço dos conhecimentos de suas propriedades várias aplicações foram surgindo e motivando cada vez mais seu estudo.

No caso do estudo das cônicas no ensino médio, fazer uma abordagem com extremo rigor e formalismo pode contribuir para um resultado não satisfatório devido à pouca maturidade dos estudantes. Uma proposta para que este estudo possa gerar bons resultados é de que se faça uma abordagem sobre as propriedades dessas curvas e o quão importante são para diversas áreas. 


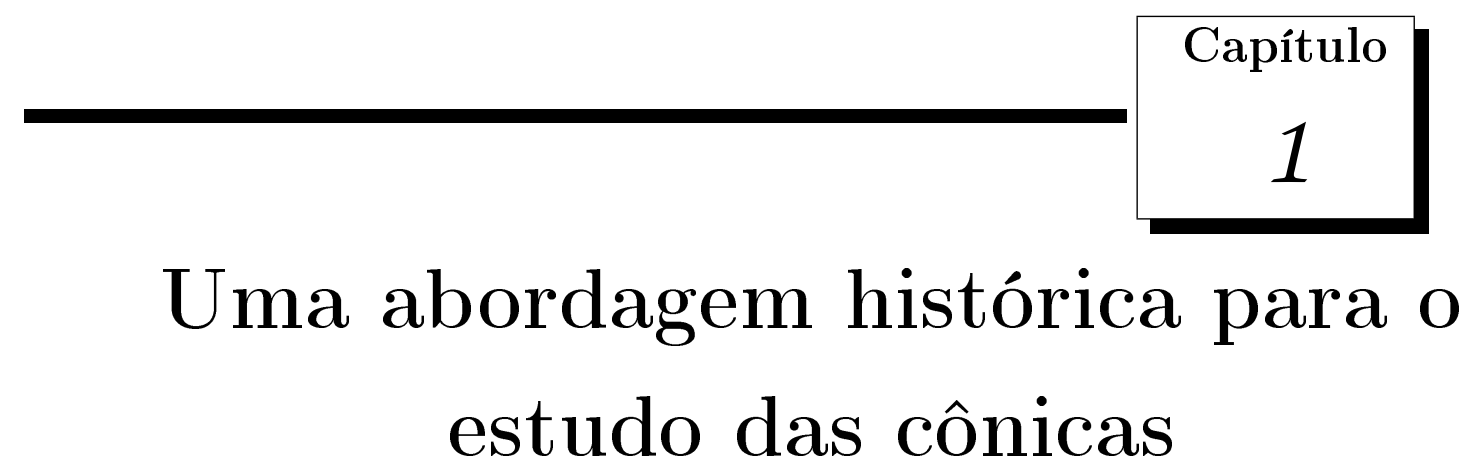

No século III a.C. três matemáticos se destacaram: Euclides, Arquimedes e Apolônio. Apolônio foi quem fez pela primeira vez uma obra bem detalhada sobre cônicas. Apolônio era cerca de vinte e cinco anos mais novo que Arquimedes, nasceu por volta de 262 a.C. em Perga, no sul da Ásia Menor. Ele era chamado pelos grandes matemáticos da época como o "Grande Geômetra" em especial por ter publicado a obra "As Cônicas", considerada o principal trabalho já desenvolvido sobre o assunto. Na referência [3] tem-se mais detalhes.

O homem já demonstrava seu interesse pelos estudos das cônicas desde os tempos mais remotos. Áreas como a Física, a Astronomia, a Economia, a Engenharia utilizam-se bastante de seus conceitos. Diversas propriedades das cônicas são demonstradas pelos métodos da Geometria Analítica, porém, muito antes da invenção desta ciência, mais precisamente no século III a.C, Apolônio de Pérgamo, da Escola de Alexandria, já havia desenvolvido e apresentado seus estudos que davam um tratamento bastante completo sobre as seções cônicas em sua obra prima "As Cônicas". Foi nesta obra que Apolônio mostrou que de um único cone podem ser obtidas todas as três seções cônicas, simplesmente variando a inclinação do plano de seção.

Antes de Apolônio os gregos tiravam as cônicas de três tipos de cones de revolução, conforme o ângulo do vértice da seção meridiana fosse menor que, igual a ou maior que um ângulo reto, referência [5]. 

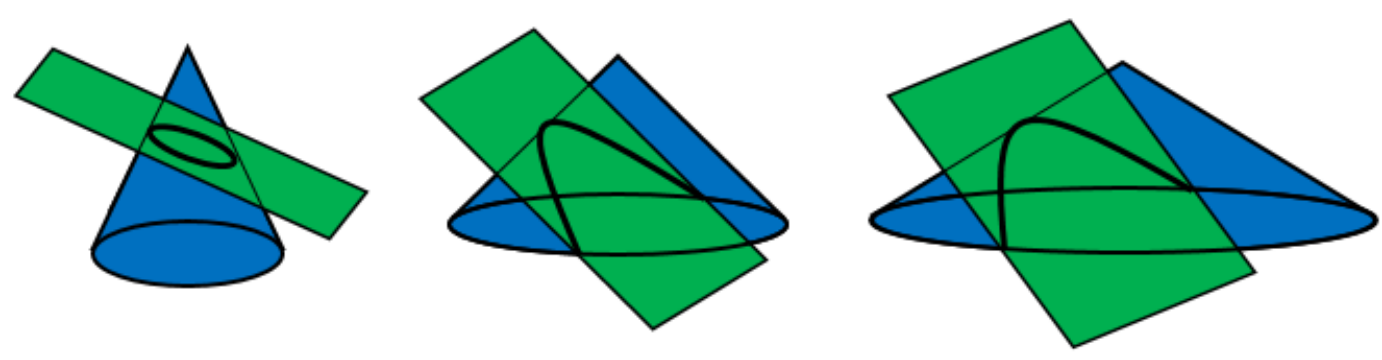

Figura 1.1: Cônicas conforme o ângulo da seção meridiana do cone

Secionando-se cada um desses tipos de cone com um plano perpendicular a uma geratriz resultam respectivamente uma elipse, uma parábola e uma hipérbole. Apolônio, em seu livro I do tratado sobre Cônicas, demonstrou que era possível se obter todas as cônicas a partir de um único cone circular duplo, conhecido como cone circular de folhas duplas, conforme conhecemos hoje, apenas variando a inclinação do plano de seção. Com a introdução do cone duplo a hipérbole passou a ser conhecida como curva de dois ramos. Anteriormente a isso, os geômetras falavam das "duas hipérboles" em vez de dois ramos de uma única hipérbole.

Foi nesta obra, também que Apolônio introduziu os nomes elipses, parábolas e hipérboles que vieram da terminologia que os Pitagóricos usavam referentes às aplicações de áreas. Quando os Pitagóricos aplicavam um retângulo a um segmento de reta, isto é, colocavam a base do retângulo ao longo do segmento de reta, com um vértice do retângulo sobre uma extremidade do segmento, eles diziam que se tinha uma ellipisis (significando falta), parabole (significando colocar ao lado ou comparação) ou hyperbole (significando um lançamento além), conforme a base do retângulo ficava aquém do segmento de reta, coincidia com ele ou o excedia, referência [5]. Seja então $A B$ (figura ) o eixo principal de uma cônica, $P$ um de seus pontos e $Q$ o pé da perpendicular por $P$ a $A B$. Por $A$, que é o vértice da cônica, trace a perpendicular a $A B$ e marque nela uma distância $A R$ igual ao que chamamos hoje latus rectum, ou parâmetro $p$, da cônica. Aplique a $A R$ um retângulo tendo $A Q$ como um dos lados e de área igual a $(P Q)^{2}$. Conforme a aplicação fique aquém do segmento de reta $A R$, coincida com ele ou exceda, Apolônio chamava a cônica de elipse, parábola ou hipérbole. 


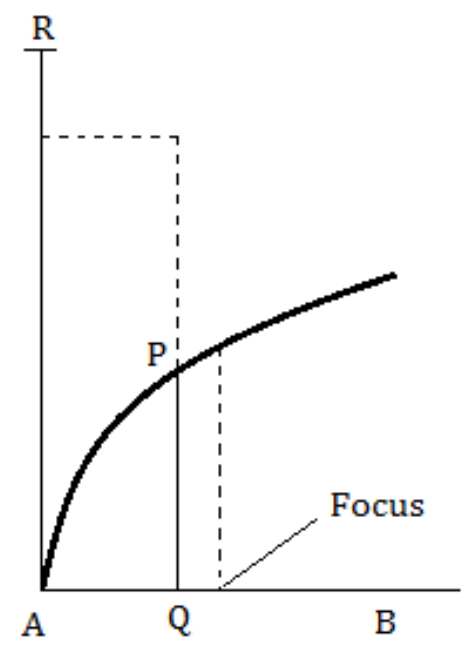

Figura 1.2: Retângulo aplicado ao segmento $A B$

Um outro aspecto interessante tratado na obra "As Cônicas" foi que Apolônio provou que duas parábolas quaisquer são sempre semelhantes. Isso é revelador, pois intuitivamente tem-se a ideia de que existem parábolas com aberturas mais acentuadas e menos acentuadas, veja nas figuras 1.3, 1.4 e 1.5

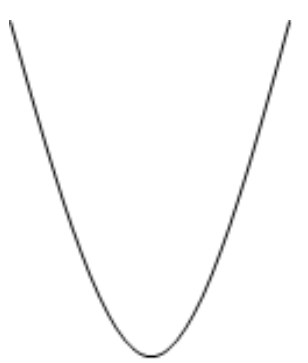

Figura 1.3: Parábola 1

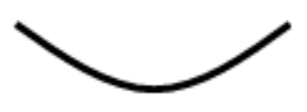

Figura 1.4: Parábola 2

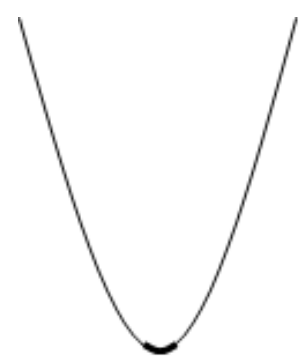

Figura 1.5: Parábolas sobrepostas

Na verdade, o que acontece é que estamos vendo a parábola numa perspectiva mais "próxima" ou mais "distante". Na figura 1.5 destaca-se a parábola da figura 1.4 coincidindo com a figura 1.3.

Para o leitor interessado em mais estudos da história de cônicas tem-se as bibliografias [3] e [5]. 


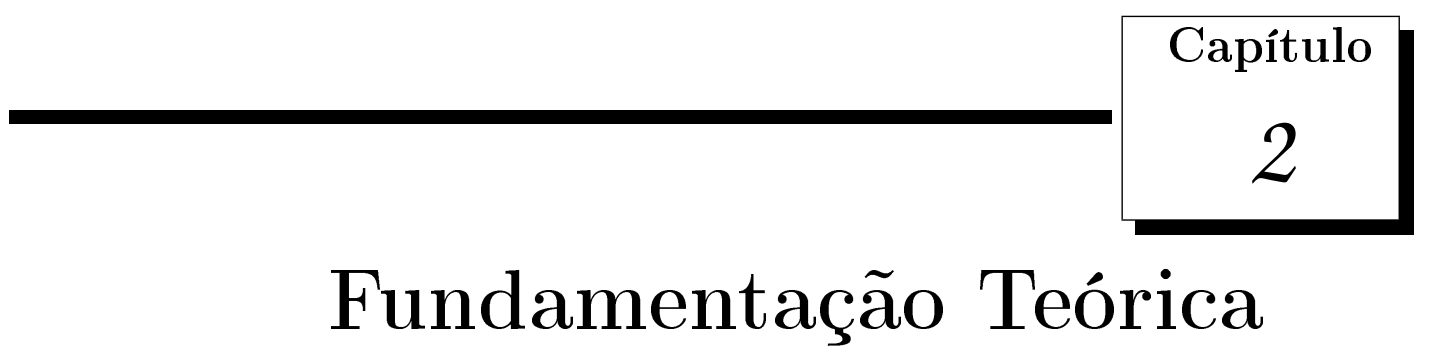

\subsection{Abordagem Geométrica}

As seções cônicas elipse, hipérbole e parábola tem esses nomes por terem sido inicialmente definidas como interseções de um plano com um cone, mais precisamente, num cone circular de folhas duplas.

O cone é considerado como tendo duas folhas, estendendo-se indefinidamente em ambas as direções (Figura 2.1). Uma parte do cone circular reto com duas folhas está na Figura 2.2. Uma geratriz do cone é uma reta que está sobre o cone, todas as geratrizes de um cone contêm o ponto $\mathrm{V}$, chamado vértice, indicado na figura 2.1

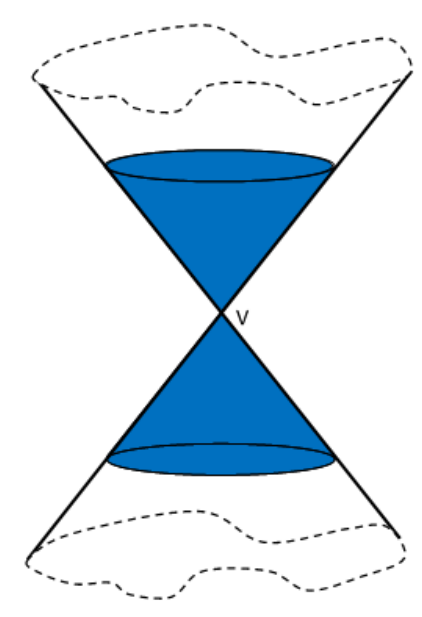

Figura 2.1: Cone de folhas duplas

À medida que se muda a inclinação do plano em relação às geratrizes do cone obtém- 
se as curvas elipses, parábolas e hipérboles. A figura 2.2 apresenta as três cônicas, cujas respectivas explicações aparecerão em seguida.

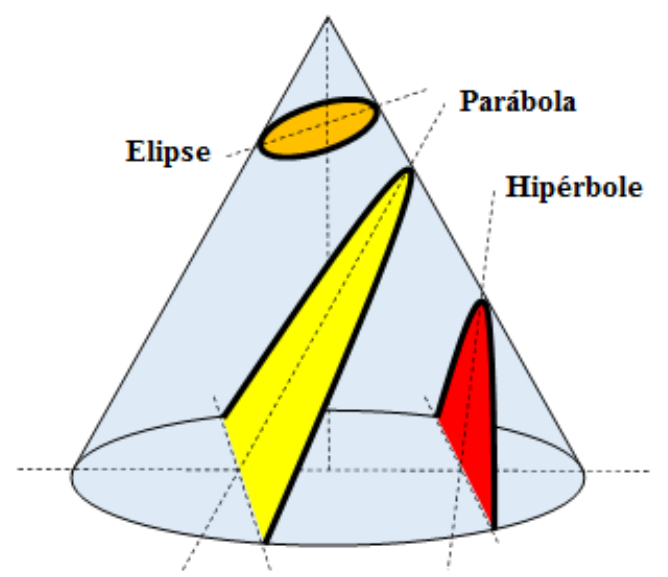

Figura 2.2: Elipse, parábola e hipérbole no cone

Se um plano intersecta o cone de modo que não seja paralelo a qualquer geratriz do cone, a curva gerada é uma elipse. Veja um exemplo na Figura 2.3

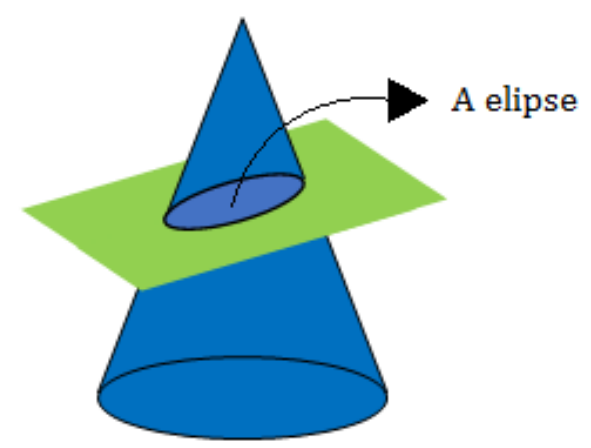

Figura 2.3: Elipse

Observe que na Figura 2.3 o plano que seciona o cone não é paralelo a nenhuma das geratrizes do cone.

Em especial, se o plano for perpendicular ao eixo de simetria do cone, a curva gerada é uma circunferência. Como neste caso, o plano não é paralelo, também, a qualquer geratriz do cone, tem-se que a circunferência é um caso particular da elipse (Figura 2.4). 


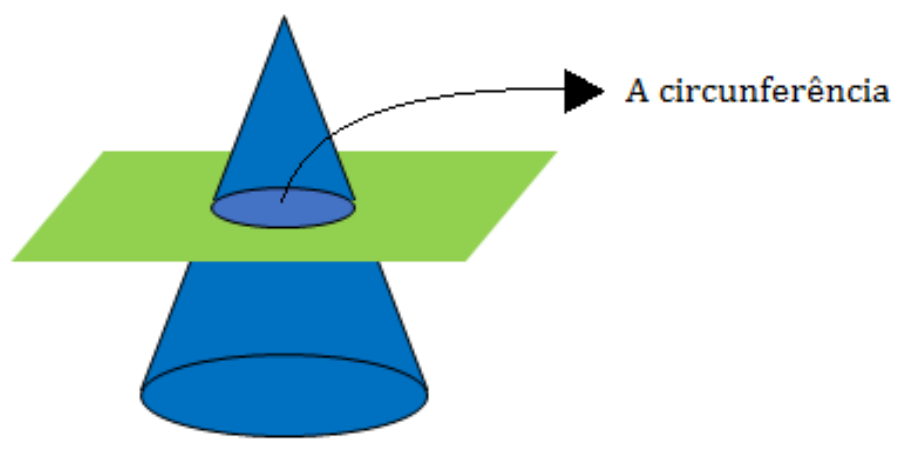

Figura 2.4: Circunferência

Se inclinarmos mais o plano, de modo que fique paralelo a uma e somente uma geratriz do cone, a curva gerada é uma parábola. Vejo o exemplo na Figura 2.5.

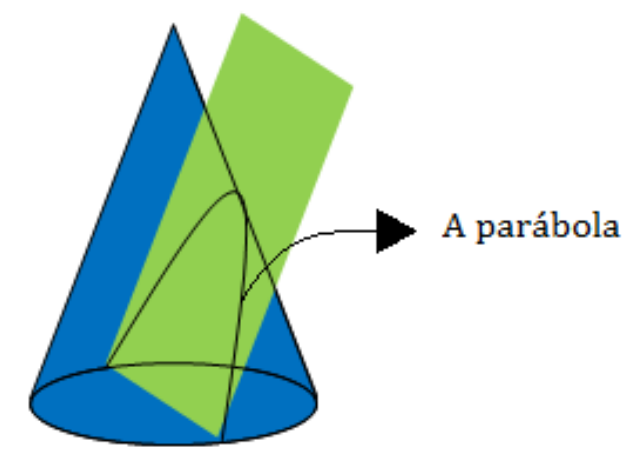

Figura 2.5: Parábola

Se inclinarmos o plano ainda mais, de modo que fique paralelo a duas geratrizes, então a curva gerada será uma hipérbole. Veja Figura 2.6. Este é o único caso em que o plano seciona os dois cones no cone de folhas duplas. O corte gera, portanto, duas curvas, uma na parte inferior e outra na parte superior. Consequentemente, a curva hipérbole é composta de um par de ramos. É importante ressaltar que é um equívoco dizer que são duas hipérboles. O correto é dizer que trata-se de uma hipérbole que possui dois ramos. 


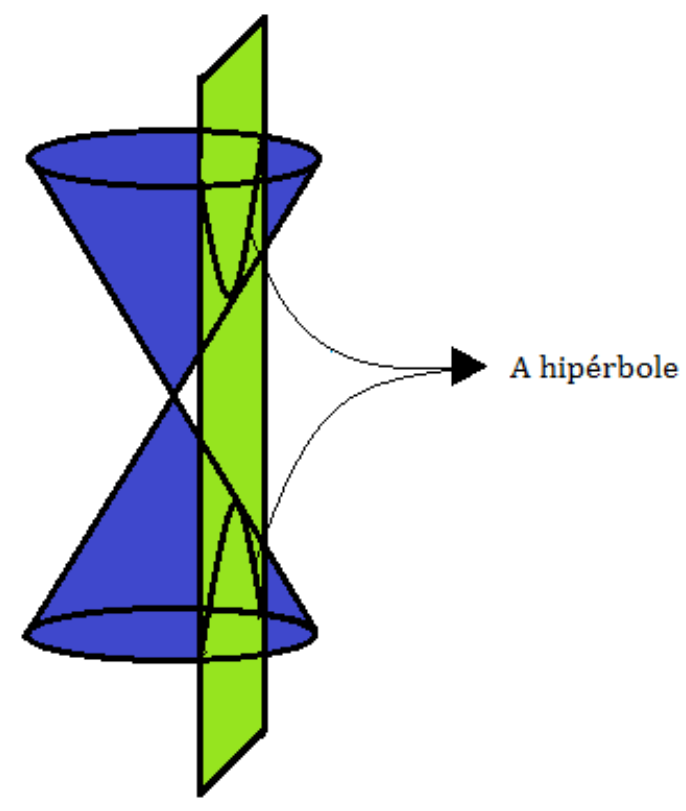

Figura 2.6: Hipérbole

\subsection{Abordagem Analítica}

O estudo analítico das cônicas permitiu que o homem conhecesse suas propriedades e que desse grandes avanços em diversas áreas. Neste ponto, as demonstrações dadas são baseadas na obra de Geraldo Ávila: Cálculo 2 - Funções de uma variável, na referência [2].

Antes, é importante lembrar a definição de lugar geométrico. Conforme Iezzi, referência [6]: Uma figura é um lugar geométrico (L.G.) de pontos quando todos os seus pontos, e apenas eles, têm uma certa propriedade comum.

\subsubsection{Elipse}

A elipse é definida como sendo o lugar geométrico dos pontos $P$ do plano, cuja soma das distâncias a dois pontos fixos $F_{1}$ e $F_{2}$ é constante. Isto significa que se $P, P^{\prime}, P^{\prime \prime}$ etc., são pontos da elipse, então (Figura 2.7)

$$
P F_{1}+P F_{2}=P^{\prime} F_{1}+P^{\prime} F_{2}=P^{\prime \prime} F_{1}+P^{\prime \prime} F_{2}=\text { constante }
$$




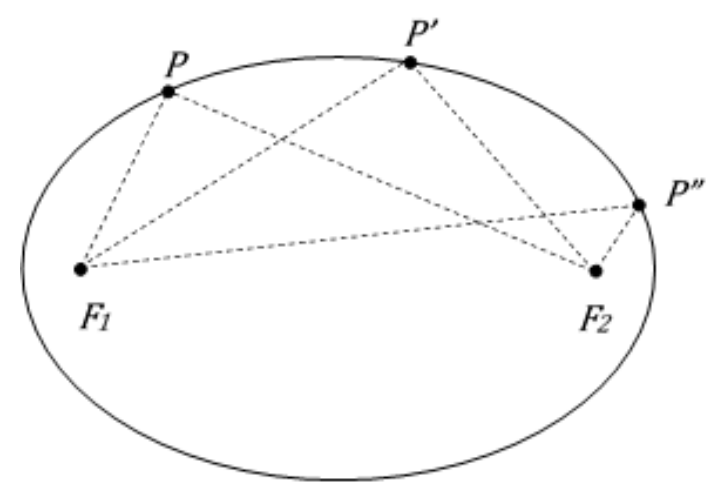

Figura 2.7: Elipse como lugar geométrico

Os pontos $F_{1}$ e $F_{2}$ são chamados os focos da elipse e o ponto médio do segmento $F_{1} F_{2}$ é o seu centro. Para obtermos a equação cartesiana dessa curva, é conveniente escolher o sistema de eixos com origem em seu centro e eixos $O x$ coincidentes com $O F_{1}$ (Figura 2.8). Sejam $-c$ e $c>0$ as abscissas de $F_{1}$ e $F_{2}$, respectivamente e seja $2 a$ a constante $P F_{1}+P F_{2}$, onde $P=(x, y)$ é um ponto arbitrário da elipse. Pondo $d_{1}=P F_{1}$ e $d_{2}=P F_{2}$, e notando que $d_{1}=\sqrt{(x+c)^{2}+y^{2}}$ e $d_{2}=\sqrt{(x-c)^{2}+y^{2}}$,

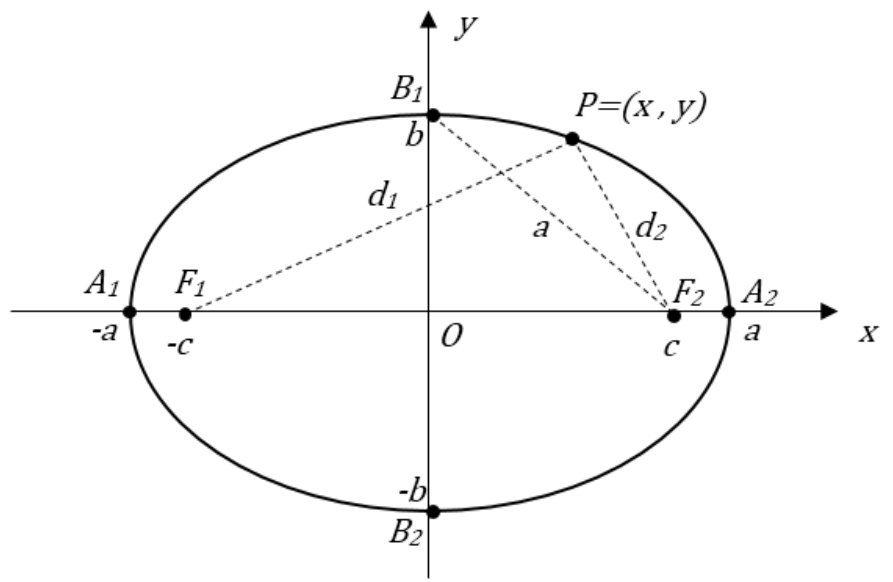

Figura 2.8: A elipse no sistema de coordenadas cartesianas

a equação da elipse

$$
d_{1}+d_{2}=2 a
$$

assume a forma

$$
\sqrt{(x+c)^{2}+y^{2}}+\sqrt{(x-c)^{2}+y^{2}}=2 a .
$$

Para eliminarmos os radicais, elevamos ambos os membros dessa equação ao quadrado, 
donde resulta

$$
(x+c)^{2}+y^{2}+(x-c)^{2}+y^{2}+2 \sqrt{(x+c)^{2}+y^{2}} \sqrt{(x-c)^{2}+y^{2}}=4 a^{2} \Rightarrow
$$

$x^{2}+2 x c+c^{2}+y^{2}+x^{2}-2 x c+c^{2}+y^{2}+2 \sqrt{\left(x^{2}+2 x c+c^{2}+y^{2}\right)\left(x^{2}-2 x c+c^{2}+y^{2}\right)}=4 a^{2} \Rightarrow$

$$
\begin{gathered}
2 x^{2}+2 c^{2}+2 y^{2}+2 \sqrt{\left(x^{2}+2 x c+c^{2}+y^{2}\right)\left(x^{2}-2 x c+c^{2}+y^{2}\right)}=4 a^{2} \Rightarrow \\
x^{2}+c^{2}+y^{2}+\sqrt{\left(x^{2}+2 x c+c^{\Rightarrow} 2+y^{2}\right)\left(x^{2}-2 x c+c^{2}+y^{2}\right)}=2 a^{2} \Rightarrow \\
\sqrt{\left(x^{2}+c^{2}+y^{2}+2 c x\right)\left(x^{2}+c^{2}+y^{2}-2 c x\right)}=2 a^{2}-x^{2}-c^{2}-y^{2} .
\end{gathered}
$$

Elevando ambos os membros ao quadrado novamente, obtem-se:

$$
\begin{gathered}
\left(x^{2}+c^{2}+y^{2}+2 c x\right)\left(x^{2}+c^{2}+y^{2}-2 c x\right)=\left(2 a^{2}-x^{2}-c^{2}-y^{2}\right)^{2} \\
x^{4}+c^{2} x^{2}+x^{2} y^{2}-2 c x^{3}+c^{2} x^{2}+c^{4}+c^{2} y^{2}-2 c^{3} x+x^{2} y^{2}+c^{2} y^{2}+y^{4}-2 c x y^{2}+2 c x^{3}+ \\
+2 c^{3} x+2 c x y^{2}-4 c^{2} x^{2}= \\
4 a^{4}-2 a^{2} x^{2}-2 a^{2} c^{2}-2 a^{2} y^{2}-2 a^{2} x^{2}+x^{4}+c^{2} x^{2}+x^{2} y^{2}-2 a^{2} c^{2}+ \\
+c^{2} x^{2}+c^{4}+c^{2} y^{2}-2 a^{2} y^{2}+x^{2} y^{2}+c^{2} y^{2}+y^{4} \Rightarrow \\
x^{4}+c^{4}+y^{4}+2 c^{2} x^{2}+2 x^{2} y^{2}+2 c^{2} y^{2}-4 c^{2} x^{2}= \\
4 a^{4}+x^{4}+y^{4}-4 a^{2} x^{2}-4 a^{2} c^{2}-4 a^{2} y^{2}+2 c^{2} x^{2}+2 x^{2} y^{2}+2 c^{2} y^{2} \Rightarrow \\
-4 c^{2} x^{2}=4 a^{4}-4 a^{2} x^{2}-4 a^{2} c^{2}-4 a^{2} y^{2} \Rightarrow \\
-c^{2} x^{2}=a^{4}-a^{2} x^{2}-a^{2} c^{2}-a^{2} y^{2} \Rightarrow
\end{gathered}
$$




$$
\begin{aligned}
& a^{2} x^{2}-c^{2} x^{2}+a^{2} y^{2}=a^{4}-a^{2} c^{2} \Rightarrow \\
& \left(a^{2}-c^{2}\right) x^{2}+a^{2} y^{2}=a^{2}\left(a^{2}-c^{2}\right) .
\end{aligned}
$$

Note que $a>c$, logo, pondo $b^{2}=a^{2}-c^{2}$ e dividindo ambos os membros por $a^{2} b^{2}$, obtemos

$$
\begin{gathered}
\frac{b^{2} x^{2}}{a^{2} b^{2}}+\frac{a^{2} y^{2}}{a^{2} b^{2}}=\frac{a^{2} b^{2}}{a^{2} b^{2}} \Rightarrow \\
\frac{x^{2}}{a^{2}}+\frac{y^{2}}{b^{2}}=1
\end{gathered}
$$

que representa a equação canônica da elipse nas condições estabelecidas.

\subsubsection{Hipérbole}

Definimos hipérbole como sendo o lugar geométrico dos pontos $P$ do plano cuja diferença das distâncias a dois pontos fixos $F_{1}$ e $F_{2}$ é constante (Figura 2.9).

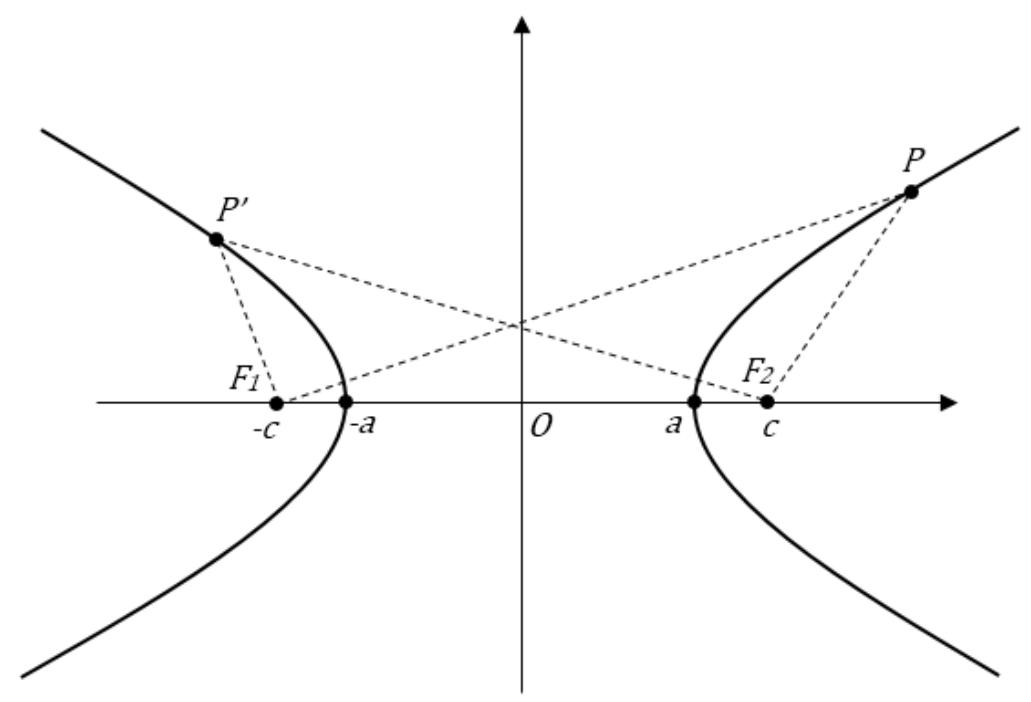

Figura 2.9: Hipérbole como lugar geométrico

Como no caso da elipse, $F_{1}$ e $F_{2}$ são os focos da hipérbole. Procedendo exatamente como na seção 2.1, ambas as equações

$$
P F_{1}-P F_{2}=2 a
$$


$\mathrm{e}$

$$
P^{\prime} F_{2}-P^{\prime} F_{1}=2 a
$$

nos conduzem à equação

$$
\left(a^{2}-c^{2}\right) x^{2}-a^{2} y^{2}=a^{2}\left(a^{2}-c^{2}\right) .
$$

Agora, $c>a$, enquanto que na elipse tínhamos , $a>c$. Portanto, pondo $b^{2}=c^{2}-a^{2}$ e dividindo ambos os membro por $a^{2} b^{2}$, obtemos a equação

$$
\begin{gathered}
\frac{b^{2} x^{2}}{a^{2} b^{2}}-\frac{a^{2} y^{2}}{a^{2} b^{2}}=\frac{a^{2} b^{2}}{a^{2} b^{2}} \Rightarrow \\
\frac{x^{2}}{a^{2}}-\frac{y^{2}}{b^{2}}=1
\end{gathered}
$$

que é a equação canônica da hipérbole.

\subsubsection{Parábola}

Vamos definir a parábola como sendo o lugar geométrico dos pontos $P$ do plano que são equidistantes de uma reta fixa e de um ponto fixo. A reta é chamada de diretriz e o ponto fixo é o foco da parábola. Para obtermos a equação da parábola em forma simples, vamos considerar um sistema cartesiano de forma tal que a diretriz seja a reta de equação $y=-p$ e o foco o ponto $F=(0, p)$. Então $P=(x, y)$ é um ponto genérico da parábola, se, e somente se (Figura 2.10), $P F^{2}=P A^{2}$, isto é

$$
(y-p)^{2}+x^{2}=(y+p)^{2} .
$$

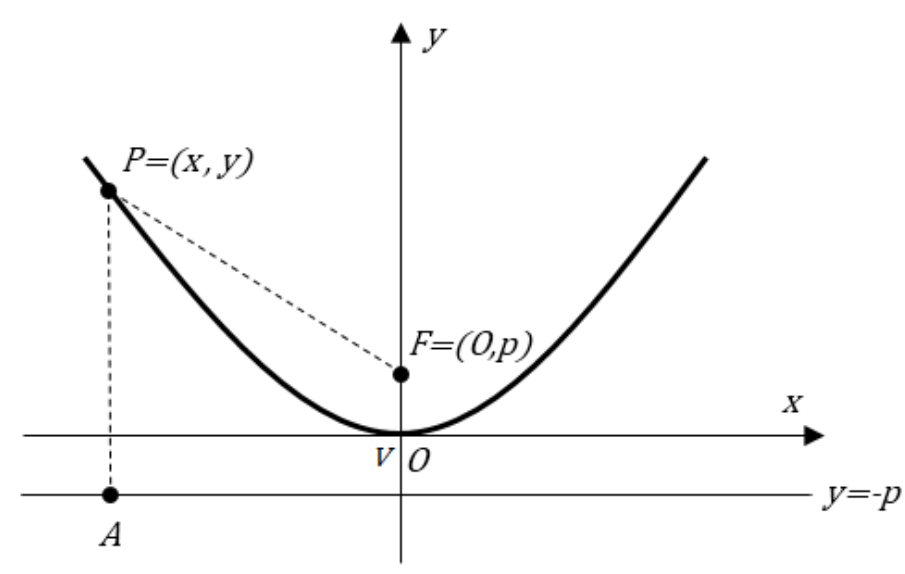

Figura 2.10: Parábola como lugar geométrico 
Mas isto equivale a

$$
-2 p y+x^{2}=2 p y
$$

ou seja,

$$
x^{2}=4 p y,
$$

que é a forma canônica da equação da parábola.

A reta que passa pelo foco e é perpendicular à diretriz chama-se eixo da parábola, e o ponto $V$ em que a parábola intersecta o eixo chama-se vértice. Na figura 2.10, o eixo é evidentemente o eixo das ordenadas, o vértice é a origem e o foco pertencente ao semi-eixo positivo $O y$.

Se trocarmos a posição da parábola com relação aos eixos coordenados, sua equação naturalmente mudará. Três outras posições simples, cada uma com sua correspondente equação, são apresentadas nas figuras 2.11, 2.12 e 2.13.

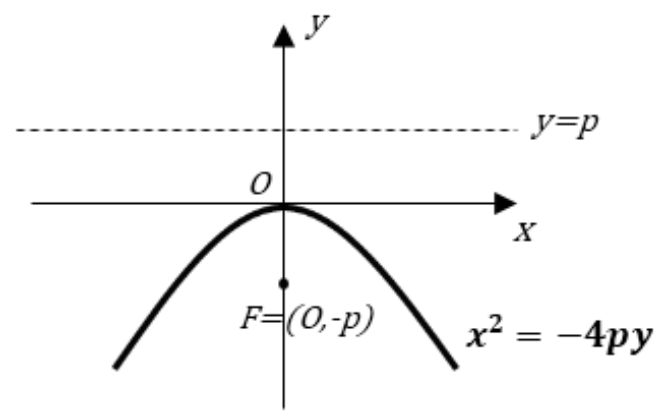

Figura 2.11: Parábola com vértice na origem e foco pertencente ao semi-eixo negativo $O y$

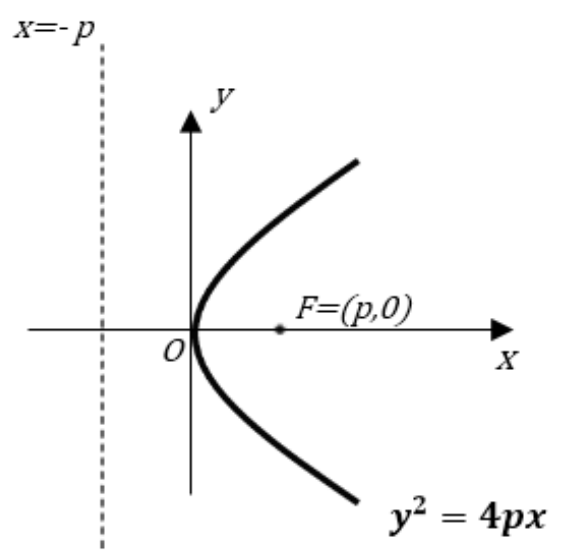

Figura 2.12: Parábola com vértice na origem e foco pertencente ao semi-eixo positivo $O x$ 


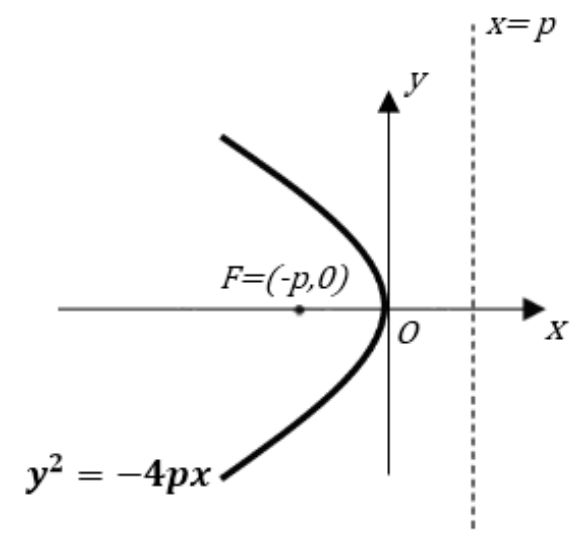

Figura 2.13: Parábola com vértice na origem e foco pertencente ao semi-eixo negativo $O x$

Observação: as equações deduzidas acima foram consideradas apenas com os focos nos eixos das abscissas e das ordenadas

\subsection{Abordagem por meio de coordenadas polares}

Uma forma também muito interessante de se abordar as curvas cônicas é por meio de coordenadas polares. Como este assunto não faz parte do programa do ensino médio, veremos aqui, inicialmente, uma introdução do que vem a ser coordenadas polares e em seguida veremos as abordagens das cônicas. A referência [8] foi usada como fonte de consulta nesta seção.

\subsubsection{Coordenadas Polares}

Num sistema de coordenadas cartesianas associamos um par ordenado de um números a cada ponto do plano de acordo com seu deslocamento horizontal e vertical. São as denominadas coordenadas retangulares. Essa ideia é bem difundida no ensino médio, porém, existe uma outra maneira, também tão poderosa de se associar um par ordenado de números a cada ponto do plano, mas não pelo deslocamento horizontal e vertical descrito, e sim pela sua direção a partir da origem, e por sua distância da origem. Isso é que denomina-se coordenadas polares.

Um ponto é localizado por meio de sua distância e direção da origem.

Considere um ponto $P$, no plano e suas coordenadas $(r, \theta)$, onde $r$ representa a distância de $P$ à origem e $\theta$, a direção a partir da origem.

Na Figura 2.14, tem-se $P=(r, \theta)$ 


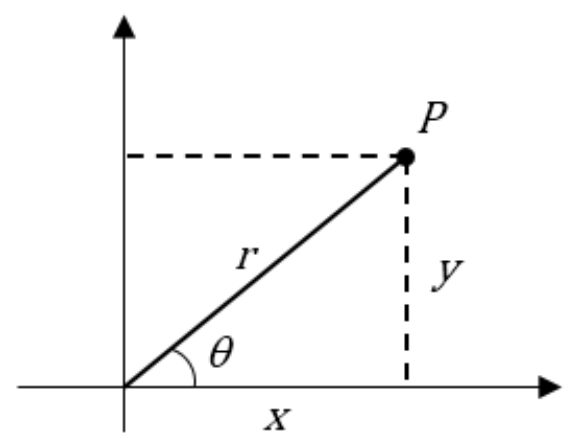

Figura 2.14: Coordenadas Polares

A direção é especificada por um ângulo $\theta$, em radianos, medida a partir do semi-eixo positivo das abscissas, sendo positivo se medido no sentido anti-horário e negativo se, no horário. A distância é dada pela distância orientada $r$, medida a partir da origem ao longo do lado terminal do ângulo $\theta$. Portanto, o par ordenado $(r, \theta)$ representa a coordenada polar do ponto $P$.

É possível estabelecer uma conexão entre as coordenadas retangulares e as polares. Pela Figura 2.14 é imediato perceber que:

$$
\begin{aligned}
& x=r \cdot \cos \theta \\
& y=r \cdot \operatorname{sen} \theta \\
& r^{2}=x^{2}+y^{2}
\end{aligned}
$$

e

$$
\tan \theta=\frac{y}{x}
$$

Observa-se que, se $r$ e $\theta$ são conhecidos, as equações permitem encontrar $x$ e $y$ e se $x$ e $y$ são conhecidos, as equações também permitem encontrar valores para $r$ e $\theta$. É importante ressaltar que, ao usar essas equações, é necessário tomar cuidado para que o sinal de $r$ e a escolha de $\theta$ sejam compatíveis com o quadrante em que o ponto dado $(x, y)$ está. 
Exemplo 1: Vamos determinar as coordenadas polares de um ponto que tem como coordenadas retangulares o par $(-1, \sqrt{3})$.

Solução: Temos $r= \pm \sqrt{1+3}= \pm 2$ e $\tan \theta=-\sqrt{3}$.

O ponto se encontra no segundo quadrante, e usando os conhecimentos de trigonometria concluímos que podemos escolher $r=2$ e $\theta=2 \pi / 3$. Assim, um par de coordenadas polares para o ponto é $\left(2, \frac{2 \pi}{3}\right)$. Um outro par aceitável obtemos com $r=-2$ e $\theta=-\frac{\pi}{3}$, ou seja, o par $\left(-2,-\frac{\pi}{3}\right)$. A Figura 2.15 é a representação gráfica deste ponto em sua coordenada polar.

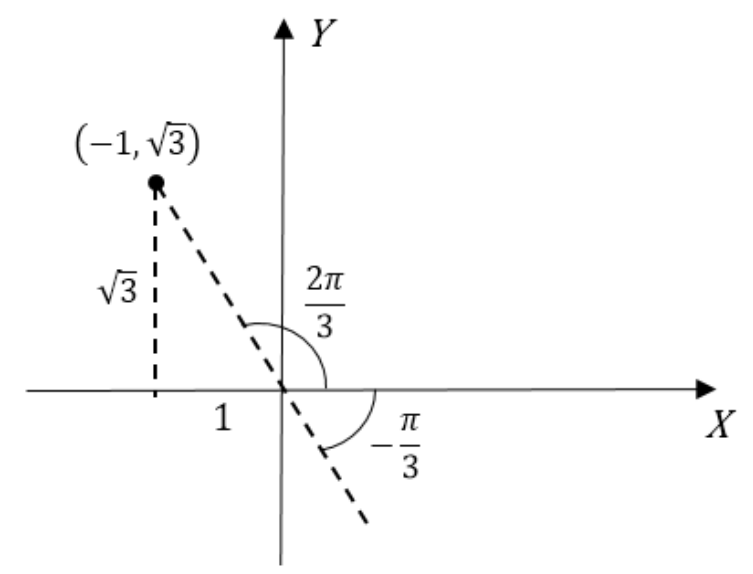

Figura 2.15: Representação gráfica em do ponto $(-1, \sqrt{3})$ em coordenadas polares

Assim como no caso de coordenadas retangulares, o gráfico de uma equação polar $F(r, \theta)=0$ é o conjunto de todos os pontos $P=(r, \theta)$ cujas coordenadas polares satisfazem a equação. Uma vez que o ponto $P$ tem muitos pares diferentes de coordenadas, é necessário estabelecer explicitamente que $P$ pertence ao gráfico se qualquer um de seus diferentes pares de coordenadas satisfizer a equação.

Exemplo 2: Mostre que ambos os pontos. $\left(1, \frac{\pi}{2}\right)$ e $\left(1, \frac{3 \pi}{2}\right)$ pertencem ao gráfico de $r^{2}=\operatorname{sen}(\theta)$

Solução: O ponto $\left(1, \frac{\pi}{2}\right)$ está no gráfico porque as coordenadas dadas satisfazem a equação:

$r^{2}=\operatorname{sen}(\theta)$, ou seja, $1^{2}=\operatorname{sen}\left(\frac{\pi}{2}\right)$. Por outro lado, o ponto $\left(1, \frac{3 \pi}{2}\right)$ está no gráfico, embora $0^{2} \neq \operatorname{sen}\left(\frac{3 \pi}{2}\right)$. A razão desse comportamento aparentemente estranho é que $\left(-1, \frac{\pi}{2}\right)$ tam- 
bém é um par de coordenadas do ponto $\left(1, \frac{3 \pi}{2}\right)$ e $(-1)^{2}=\operatorname{sen}\left(\frac{\pi}{2}\right)$.

\subsubsection{Equação da Elipse em cordenadas Polares}

Considere uma elipse com focos $O=(0,0)$ e $F=(-2 e a, 0)$ e seja $P=(x, y)$ um ponto dessa curva, conforme Figura 2.16, de modo que a soma das distâncias do ponto $P$ até $O$ e $F=2 a$. Como a distância entre os dois focos deve ser menor que $2 a$ tem-se que $0<e<1$, referência [9].

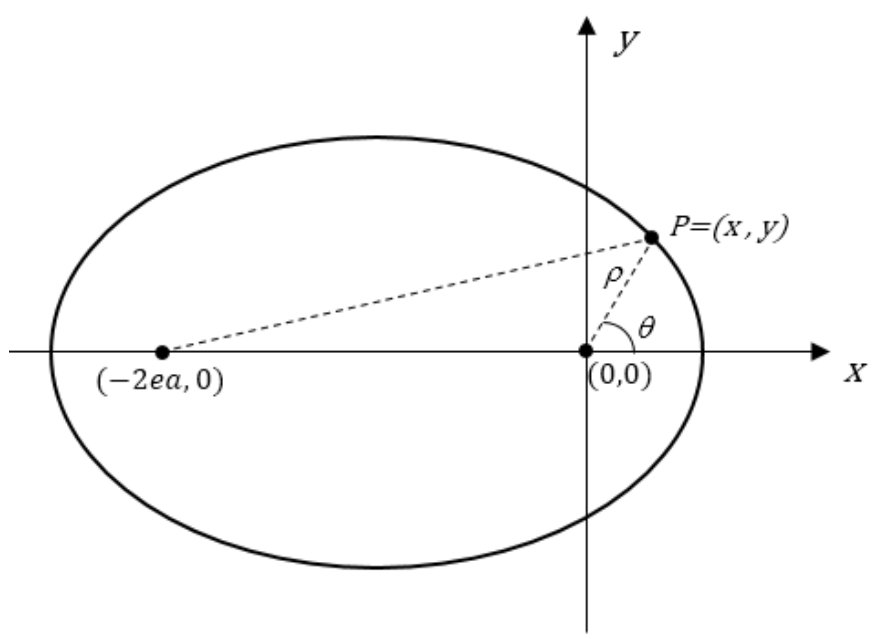

Figura 2.16: Elipse em coordenadas polares

Pela definição da elipse sabemos que

$$
d(P, F)+d(P, O)=2 a .
$$

Daí,

$$
\sqrt{(x+2 e a)^{2}+y^{2}}+\rho=2 a .
$$

Isolando o radical e depois elevando ao quadrado, temos

$$
(x+2 e a)^{2}+y^{2}=(2 a-\rho)^{2},
$$

ou seja,

$$
\begin{aligned}
& x^{2}+4 x e a+4 e^{2} a^{2}+y^{2}=4 a^{2}-4 a \rho+\rho^{2} \Rightarrow \\
& \left(x^{2}+y^{2}\right)-\rho^{2}+4 x e a+4 a \rho=4 a^{2}-4 e^{2} a^{2} .
\end{aligned}
$$


Substituindo $x^{2}+y^{2}$ por $\rho^{2}$ temos

$$
\begin{gathered}
\rho^{2}-\rho^{2}+4 a(x e+\rho)=4 a^{2}\left(1-e^{2}\right) \Rightarrow \\
4 a(x e+\rho)=4 a^{2}\left(1-e^{2}\right) .
\end{gathered}
$$

Como $a>0$, dividimos ambos os membros da equação por $4 a$, obtendo

$$
x e+\rho=a\left(1-e^{2}\right)
$$

Como $x=\rho \cos \theta$, pois $\rho=r$, resulta

$$
\begin{gathered}
\rho \cos \theta \cdot(e)+\rho=a\left(1-e^{2}\right) \Rightarrow \\
\rho(e \cdot \cos \theta+1)=a\left(1-e^{2}\right),
\end{gathered}
$$

ou seja,

$$
\rho=\frac{a\left(1-e^{2}\right)}{1+e \cdot \cos \theta}
$$

Fazendo $a\left(1-e^{2}\right)=\Lambda$, podemos escrever a equação polar da cônica em sua forma final

$$
\rho=\frac{\Lambda}{1+e \cdot \cos \theta}
$$

\subsubsection{Equação da Hipérbole em cordenadas Polares}

Considere agora, conforme referência [9], uma hipérbole na qual a diferença das distâncias entre os dois focos é $2 a$. Como no caso da elipse, os focos serão dados por $O$ e $F$, porém, agora deve-se ter $e>1$ de acordo com a Figura 2.17, referência [9]. 


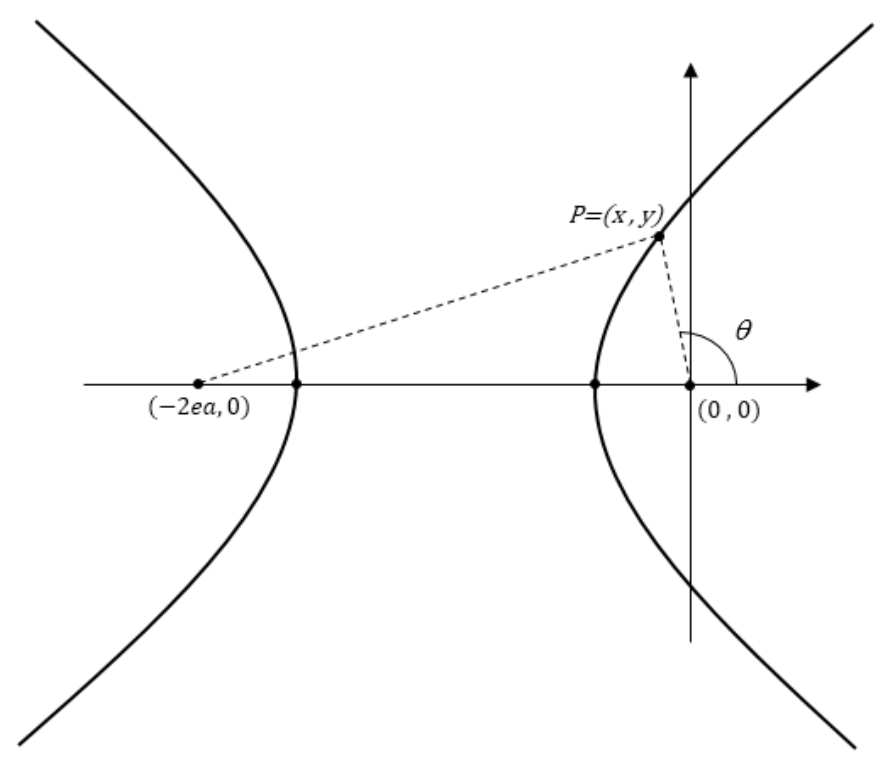

Figura 2.17: Hipérbole em coordenadas polares

Considere o ponto $P=(x, y)$. Pela definição da hipérbole sabemos que

$$
d(P, F)-d(P, O)= \pm 2 a .
$$

Escolhendo o sinal positivo na equação acima vem

$$
\sqrt{(x+2 e a)^{2}+y^{2}}-\rho=2 a .
$$

Isolando o radical e depois elevando ao quadrado, temos

$$
(x+2 e a)^{2}+y^{2}=(2 a+\rho)^{2},
$$

ou seja,

$$
x^{2}+4 x e a+4 e^{2} a^{2}+y^{2}=4 a^{2}+4 a \rho+\rho^{2} .
$$

Substituindo $x^{2}+y^{2}$ por $\rho^{2}$ e fazendo os devidos cancelamentos, temos

$$
\rho-x e=a\left(1-e^{2}\right) .
$$

Como $x=\rho \cdot \cos \theta$, pois $\rho=r$, resulta

$$
\rho-e \rho \cdot \cos \theta=a\left(1-e^{2}\right)
$$


ou seja,

$$
\rho=-\frac{a\left(1-e^{2}\right)}{1-e \cdot \cos \theta} .
$$

Como convencionamos que $(-\rho, \theta)=(\rho, \theta+\pi)$, obtemos

$$
\rho=-\frac{a\left(1-e^{2}\right)}{1-e \cdot \cos (\pi+\theta)}
$$

Sabendo que $\cos (\pi+\theta)=-\cos \theta$, encontramos finalmente

$$
\rho=\frac{a\left(1-e^{2}\right)}{1+e \cdot \cos \theta}
$$

Como definimos $a\left(1-e^{2}\right)=\Lambda$, temos a equação polar da cônica em sua forma final

$$
\rho=\frac{\Lambda}{1+e \cdot \cos \theta}
$$

Observe que se a escolha do sinal, na equação, fosse negativo, com cálculos análogos chegaríamos a mesma equação da hipérbole.

\subsubsection{Equação da Parábola em cordenadas Polares}

Considere agora a parábola como o conjunto de pontos $P$ tais que a distância de $P$ a $O$ é igual a distância até a reta $x=a$, conforme Figura 2.18, referência [9].

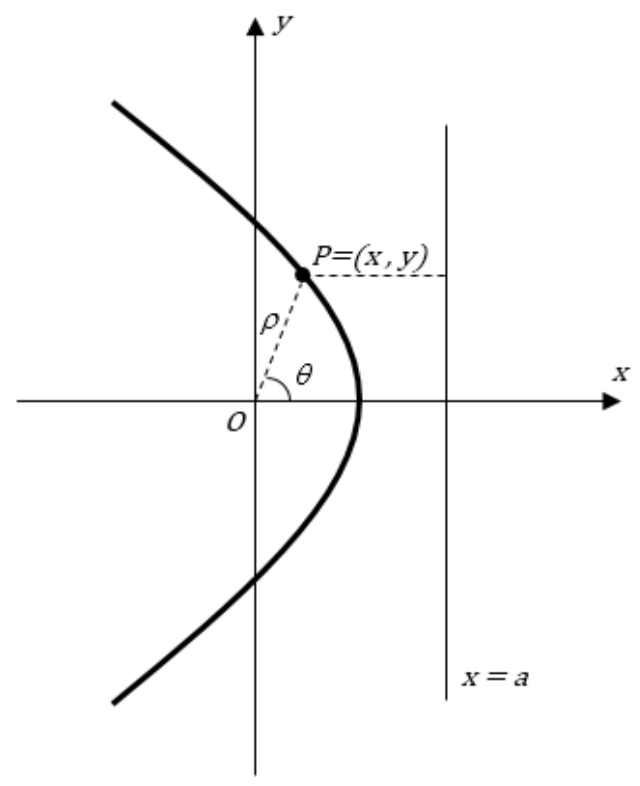

Figura 2.18: Parábola em coordenadas polares 
Daí,

$$
\sqrt{x^{2}+y^{2}}=a-\rho \cdot \cos \theta
$$

ou seja,

$$
\begin{gathered}
\rho=a-\rho \cdot \cos \theta \Rightarrow \\
\rho+\rho \cdot \cos \theta=a .
\end{gathered}
$$

Finalmente obtemos a equação polar da cônica na forma

$$
\rho=\frac{a}{1+\cos \theta} .
$$

Agora, para todo $\Lambda$ e $e$ números reais, considere a equação

$$
\rho=\frac{\Lambda}{1+e \cdot \cos \theta}
$$

Simplificando a expressão, temos

$$
r=\Lambda-r \cdot e \cos \theta
$$

Elevando ao quadrado vem

$$
r^{2}=(\Lambda-r \cdot e \cos \theta)^{2}
$$

ou seja,

$$
r^{2}=\Lambda^{2}-2 \Lambda r e \cos \theta+r^{2} e^{2} \cos ^{2} \theta
$$

Como $r^{2}=x^{2}+y^{2}$ e $x=r \cdot \cos \theta$, pois $\rho=r$, podemos escrever essa última expressão como

$$
\left(1-e^{2}\right) x^{2}+y^{2}=\Lambda^{2}-2 \Lambda e x
$$

Observe que todas as cônicas têm a mesma equação polar. O que define de qual curva se trata é simplesmente o valor de $e$. Caso tenhamos $0<e<1$, teremos uma elipse, pois os coeficientes dos termos quadráticos têm o mesmo sinal. Se $e>1$, teremos uma hipérbole, pois os coeficientes dos termos quadráticos têm sinais trocados. Finalmente, se $e=1$, teremos uma parábola, pois um dos termos quadráticos será nulo. 
Dessa forma,

$$
\left(1-e^{2}\right) x^{2}+y^{2}=\Lambda^{2}-2 \Lambda e x
$$

é uma equação geral de cônica em coordenadas polares. 


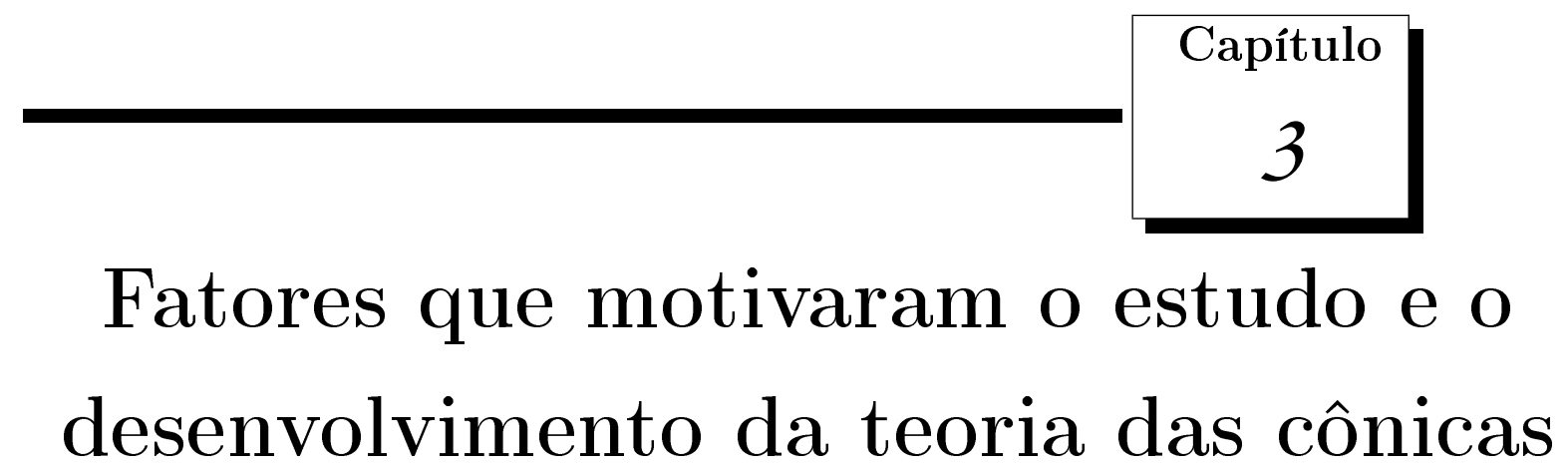

Sem dúvida, a maior importância que se pode dar ao estudo das cônicas está relacionado às suas propriedades refletoras. Foram essas propriedades que motivaram pensadores como Galileu Galilei (1564-1642) a construir um telescópio para observação astronômica. Utilizando as propriedades refletoras da hipérbole, em 1609, Galileu construiu telescópios mais avançados que os que existiam e com isso pode fazer observações que antes não eram possíveis como montanhas e acidentes geográficos na superfície lunar, descobriu que Vênus passa por fases como a Lua, notou que Saturno tem um formato alongado (devido a seus anéis), e que Júpiter possui satélites girando a sua volta. A astronomia deu um avanço considerável graças aos trabalhos de Galileu. Veja [12].

Com o avanço dos estudos sobre as propriedades refletoras das cônicas e utilizando os trabalhos de Galileu, os telescópios foram sendo aprimorados. A combinação de hipérboles e parábolas na construção dos telescópios propiciaram mais avanços ainda, chegando aos modelos que são utilizados atualmente. A importância das parábolas não para por aí. Outra área que teve bastantes avanços foram as de construções de antenas. É muito familiar a todos a antena parabólica. Muitas pessoas conhecem essas antenas, porém poucas as associam às parábolas e sabem o porquê da utilização dessa forma. Outro exemplo de aplicação das propriedades refletoras das parábolas se dá na fabricação de faróis de veículos.

As elipses também apresentam propriedades refletoras importantes e que foram utilizadas, por exemplo, no desenvolvimento de equipamentos que necessitavam concentrar a iluminação em um único ponto. Um exemplo dessa utilização se tem na confecção dos 
aparelhos de iluminação dos consultórios dentários.

Entretanto, no estudo das cônicas no ensino médio, esses aspectos são pouco mencionados. O estudo é quase sempre baseado no aspecto analítico, onde os alunos apenas fazem uso de fórmulas e não desenvolvem projetos de discussões sobre essas propriedades. O estudo de cônicas seria mais interessante para o aluno do Ensino Médio se fossem feitas abordagens dando ênfase nos aspectos relacionados às propriedades refletoras. Os alunos teriam um desenvolvimento muito mais satisfatório se fossem motivados a estudar essas propriedades e conhecessem suas aplicações.

No intuito de desenvolver este pensamento vamos apresentar essas propriedades e as aplicações práticas que foram desenvolvidas por meio delas.

\subsection{Propriedades refletoras da elipse}

A elipse é o lugar geométrico de todos os pontos cujas somas de suas distâncias à dois pontos fixos denominados focos é constante. Essa definição gera uma curva fechada. A propriedade de reflexão da elipse pode ser descrita da seguinte forma: a partir de um dos focos tracemos um segmento de reta com extremidade num ponto $P$ da elipse e que seja o ponto de tangência de uma reta $t$ qualquer. Este segmento determina com a reta $t$ um certo ângulo $\theta$. Se traçarmos outro segmento a partir desse ponto $P$ e que tenha o mesmo ângulo $\theta$ em relação à reta $t$, então este segmento irá em direção ao outro foco da elipse, referência [2].

\section{Demonstração}

Vamos provar que a reta normal à elipse num de seus pontos $P(x, y)$ é a bissetriz do ângulo $F_{1} P F_{2}$, onde $F_{1}$ e $F_{2}$ são os focos da elipse (Figura 3.1).

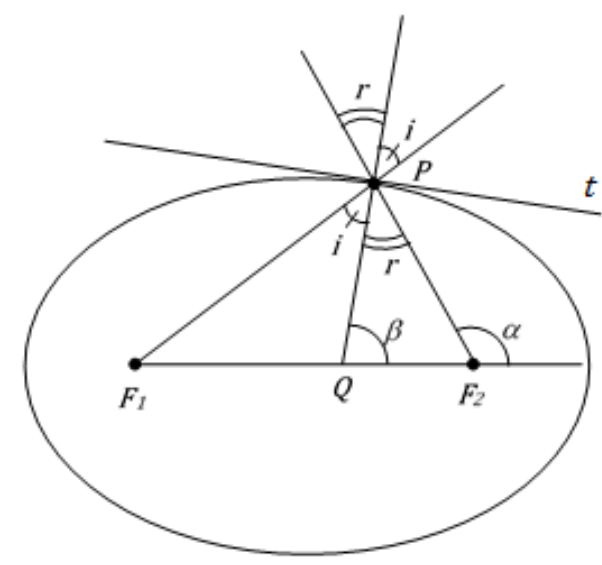

Figura 3.1: Propriedade refletora da elipse 
Sejam $m, m_{2}$ e $m_{1}$ os declives da reta normal $Q P$, da reta $F_{2} P$ e da reta $F_{1} P$, respectivamente. Sejam $\alpha$ e $\beta$ os ângulos de $F_{1} P$ e $Q P$ com o eixo $O x$, respectivamente, de sorte que $m_{2}=\tan \alpha$ e $m=\tan \beta$.

Pela trigonometria,

$$
\tan (\alpha-\beta)=\frac{\tan \alpha-\tan \beta}{1+\tan \alpha \cdot \tan \beta}
$$

Sempre com referência à Figura 3.1,

$$
r=\alpha-\beta
$$

$\log 0$

$$
\tan r=\frac{m_{2}-m}{1+m_{2} m}
$$

De maneira análoga,

$$
\tan i=\frac{m-m_{1}}{1+m m_{1}} .
$$

Devemos provar que $i=r$, ou seja $\tan i=\tan r$ :

$$
\frac{m_{2}-m}{1+m_{2} m}=\frac{m-m_{1}}{1+m m_{1}}
$$

ou ainda,

$$
\left(m_{2}+m_{1}\right)\left(m^{2}-1\right)+2\left(1-m_{1} m_{2}\right) m=0 .
$$

Como é fácil ver,

$$
m_{2}=\frac{y}{x-c}
$$

e

$$
m_{1}=\frac{y}{x+c}
$$

por outro lado,

$$
m=\frac{-b^{2} x}{a^{2} y} .
$$

Finalmente devemos verificar que esses valores de $m, m_{2}$ e $m_{1}$ satisfazem, realmente, à equação anterior. Para isso fazemos as devidas substituições no primeiro membro da equação, obtendo

$$
\frac{2 x y}{x^{2}-c^{2}} \cdot \frac{b^{4} x^{2}-a^{4} y^{2}}{a^{4} y^{2}}+\frac{2 b^{2} x}{a^{2} y} \cdot \frac{y^{2}-x^{2}+c^{2}}{x^{2}-c^{2}}=
$$




$$
\frac{2 x y\left(b^{4} x^{2}-a^{4} y^{2}\right)+2 a^{2} b^{2} x y\left(y^{2}-x^{2}+c^{2}\right)}{a^{4} y^{2}\left(x^{2}-c^{2}\right)} .
$$

Como

$$
b^{2} x^{2}+a^{2} y^{2}=a^{2} b^{2}
$$

$\mathrm{e}$

$$
c^{2}=a^{2}-b^{2}
$$

o numerador que aí aparece, exceto pelo fator $2 x y$, assume a forma

$$
\begin{gathered}
b^{4} x^{2}-a^{4} y^{2}+a^{2} b^{2} y^{2}-a^{2} b^{2} x^{2}+a^{2} b^{2} c^{2}= \\
b^{4} x^{2}-a y^{2}+b^{2}\left(a^{2} b^{2}-b^{2} x^{2}\right)-a^{2}\left(a^{2} b^{2}-a^{2} y^{2}\right)+a^{2} b^{2} c^{2}= \\
a^{2} b^{2}\left(b^{2}-a^{2}+c^{2}\right)=0,
\end{gathered}
$$

conforme queríamos demonstrar.

A partir desta propriedade foram desenvolvidas várias aplicações práticas utilizando-se elipses. Uma das aplicações mais famosas da elipse encontra-se na construção do dispositivo de iluminação dos dentistas. Nele, o dentista necessita que a iluminação seja concentrada em um único ponto, o dente do paciente; e isso é facilmente alcançado utilizando-se espelhos com a forma de um arco elíptico e com a lâmpada situada no foco mais próximo a este arco. Consequentemente os raios de luz serão todos refletidos em um único ponto, o outro foco da elipse. Quando o dentista movimenta seu dispositivo e consegue colocar o ponto de iluminação exatamente no dente a ser trabalhado, este se encontra então, na posição do outro foco da elipse. Veja no esquema abaixo indicado na Figura 3.2.

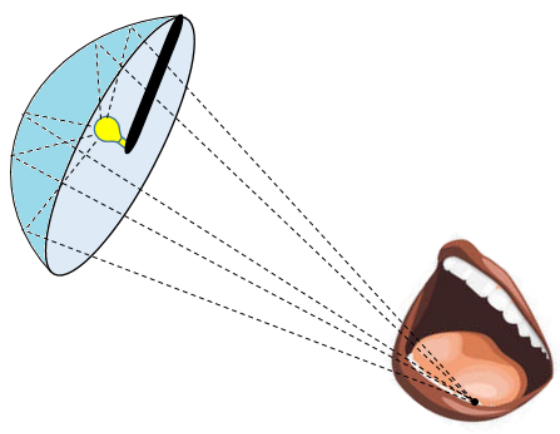

Figura 3.2: A iluminação do dentista 


\subsection{Propriedades refletoras da parábola}

No ensino médio os alunos estudam as parábolas inicialmente como o gráfico da função polinomial do segundo grau, porém, neste momento não são discutidas as propriedades refletoras de uma parábola. O mais intrigante é que essas propriedades são o que de mais interessante se pode observar numa parábola. Com o conhecimento dessas propriedades o homem pôde desenvolver a evolução na tecnologia de construções de antenas, de faróis, telescópios, dentre outros.

Neste tópico vamos investigar algumas das propriedades da parábola que vão justificar o porquê das antenas e alguns espelhos serem parabólicos.

Inicialmente vamos mostrar que a parábola pode ser considerada como a posição limite de uma elipse com um de seu focos fixo e o outro no infinito. Seja a equação canônica da elipse num sistema de coordenadas $O^{\prime} X Y$ (Figura 3.3)

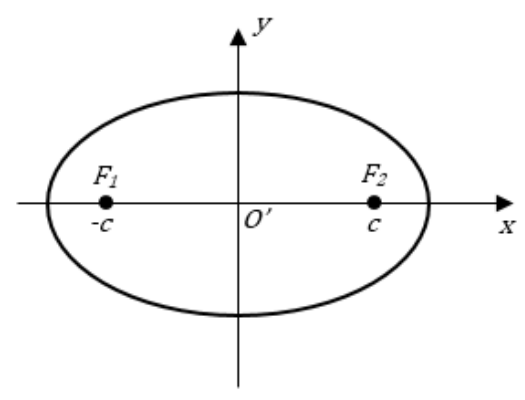

(a)

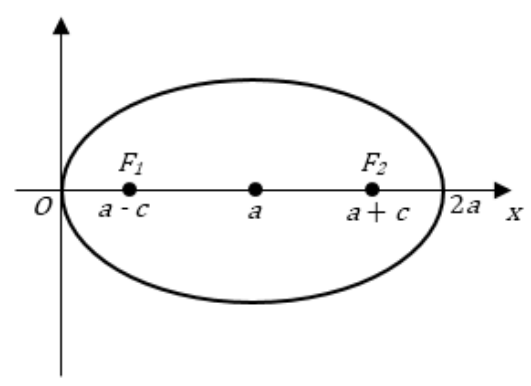

(b)

Figura 3.3: Transformação da elipse em parábola

Para deslocar o foco $F_{2}$ para o infinito, mantendo fixo o foco $F_{1}$, devemos manter fixo o número $p=a-c$ e fazer $a+c$ tender a infinito (Figura $3.3 \mathrm{~b}$ ). Com $a-c=p$ podemos obter

$$
a+c=2 a-p
$$

e

$$
b^{2}=a^{2}-c^{2}=(a-c)(a+c)=p(2 a-p),
$$

de sorte que a equação da elipse assume a forma

$$
\frac{(x-a)^{2}}{a^{2}}+\frac{y^{2}}{p(2 a-p)}=1,
$$


que equivale a

$$
(x-a)^{2}-a^{2}+\frac{a^{2} y^{2}}{p(2 a-p)}=0
$$

ou ainda,

$$
x\left(\frac{x}{a}-2\right)+\frac{a y^{2}}{p(2 a-p)}=0 .
$$

Finalmente, fazendo $a \rightarrow \infty$, obtemos a equação canônica da parábola:

$$
-2 x+\frac{y^{2}}{2 p}=0
$$

ou ainda

$$
y^{2}=4 p x
$$

Observe que os dois parâmetros, $a$ e $c$, devem tender a infinito, de maneira que $p=a-c$ fique fixo. Esta relação foi usada para eliminar $b$ e $c$, o que nos deu a equação

$$
\frac{(x-a)^{2}}{a^{2}}+\frac{y^{2}}{p(2 a-p)}=1 .
$$

Esta foi subsequentemente transformada, de maneira que, quando fizéssemos $a \rightarrow \infty$, ficássemos com os termos em $x$ e em $y^{2}$.

Note ainda que

$$
\frac{c}{a}=\frac{c}{c+p} \rightarrow 1 \operatorname{com} c \rightarrow \infty
$$

Em vista disso, a parábola é considerada uma cônica de excentricidade sempre igual a 1.

O fato de que a parábola é a posição limite de uma elipse e a propriedade de reflexão da elipse, demonstrada no tópico anterior, sugerem que a parábola tenha a seguinte propriedade de reflexão: a reta normal à parábola num de seus pontos $P=(x, y)$ é a bissetriz do ângulo $F P Q$, onde $F$ é o foco da parábola e $\overleftrightarrow{P Q}$ é uma reta paralela ao eixo Ox (Figura 3.4). 


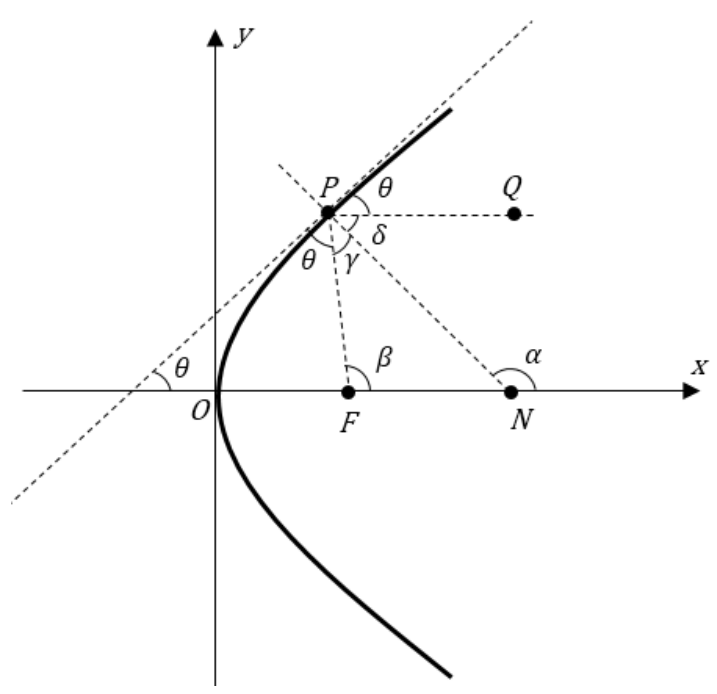

Figura 3.4: Propriedade refletora da parábola

Para estabelecermos essa propriedade, vamos provar que os ângulos $\delta=\widehat{Q P N} \mathrm{e}$ $\gamma=\widehat{N P F}$ têm tangentes iguais, onde $\overleftrightarrow{P N}$ é a normal à curva em $P$

Inicialmente observa-se que sendo $m$ e $m^{\prime}$ os declives da reta normal $\overleftrightarrow{P N}$ e da reta $\overleftrightarrow{F P}$ respectivamente, ou seja $m=\tan \alpha$ e $m^{\prime}=\tan \beta$, pela figura 3.4 temos

$$
\begin{gathered}
\beta=2 \theta \Rightarrow \\
\tan \beta=\tan (2 \theta) \Rightarrow \\
\tan \beta=m^{\prime}=\frac{2 \tan \theta}{1-\tan ^{2} \theta} .
\end{gathered}
$$

Da equação da parábola, temos

$$
y=2 \sqrt{p x}=2 \sqrt{p} \sqrt{x} .
$$

Calculando a derivada obtemos

$$
\begin{gathered}
y^{\prime}=2 \sqrt{p} \cdot(\sqrt{x})^{\prime}=\tan \theta \Rightarrow \\
\tan \theta=y^{\prime}=2 \sqrt{p} \cdot \frac{1}{2 \sqrt{x}} \Rightarrow \\
\tan \theta=y^{\prime}=\frac{\sqrt{p}}{\sqrt{x}} \Rightarrow \\
\tan \theta=y^{\prime}=\sqrt{\frac{p}{x}} .
\end{gathered}
$$


Como $\overleftrightarrow{P N}$ é a reta normal à curva em $P$, tem-se

$$
\begin{aligned}
& m=-\frac{1}{y^{\prime}} \Rightarrow \\
& m=-\sqrt{\frac{x}{p}}
\end{aligned}
$$

por outro lado,

$$
\begin{gathered}
m^{\prime}=\frac{2 \tan \theta}{1-\tan ^{2} \theta} \Rightarrow \\
m^{\prime}=\frac{2 \sqrt{\frac{p}{x}}}{1-\left(\sqrt{\frac{p}{x}}\right)^{2}} \Rightarrow \\
m^{\prime}=\frac{2 \sqrt{\frac{p}{x}}}{1-\frac{p}{x}} \Rightarrow \\
m^{\prime}=\frac{2 \sqrt{\frac{p}{x}}}{\frac{x-p}{x}} \Rightarrow \\
m^{\prime}=2 \sqrt{\frac{p}{x}} \cdot \frac{x}{x-p} \Rightarrow \\
m^{\prime}=\frac{2 x \sqrt{p}}{(x-p) \sqrt{x}} \Rightarrow \\
m^{\prime}=\frac{2 \sqrt{x p}}{x-p} \Rightarrow \\
m^{\prime}=\frac{y}{x-p} .
\end{gathered}
$$

Finalmente, vamos provar que

$$
\begin{gathered}
\tan \delta=\tan \gamma \Rightarrow \\
\tan \left(180^{\circ}-\alpha\right)=\tan (\alpha-\beta),
\end{gathered}
$$

pois, pela figura 3.4 , temos

$$
\delta=180^{\circ}-\alpha
$$

e

$$
\gamma=\alpha-\beta
$$


Daí,

$$
\begin{gathered}
\tan \left(180^{\circ}-\alpha\right)=\tan (\alpha-\beta) \Rightarrow \\
\frac{\tan 180^{\circ}-\tan \alpha}{1+\tan 180^{\circ} \cdot \tan \alpha}=\frac{\tan \alpha-\tan \beta}{1+\tan \cdot \tan \beta} \Rightarrow \\
-\tan \alpha=\frac{\tan \alpha-\tan \beta}{1+\tan \alpha \cdot \tan \beta} \Rightarrow \\
\tan \alpha=\frac{\tan \beta-\tan \alpha}{1+\tan \alpha \cdot \tan \beta} \Rightarrow \\
m=\frac{m^{\prime}-m}{1+m^{\prime} m} \Rightarrow \\
m^{\prime}\left(1-m^{2}\right)-2 m=0 .
\end{gathered}
$$

Fazendo as substituições desses valores temos

$$
\begin{gathered}
\frac{y}{x-p} \cdot\left(1-\frac{x}{p}\right)+2 \cdot \sqrt{\frac{x}{p}}=0 \Rightarrow \\
\frac{y}{x-p} \cdot \frac{p-x}{p}+2 \cdot \frac{\sqrt{x}}{\sqrt{p}}=0 \Rightarrow \\
\frac{y}{x-p} \cdot \frac{x-p}{-p}+2 \cdot \frac{\sqrt{x}}{\sqrt{p}}=0 \Rightarrow \\
-\frac{y}{p}+2 \cdot \frac{\sqrt{x p}}{p}=0 \Rightarrow \\
-\frac{1}{p}(y-2 \sqrt{x p})=0 .
\end{gathered}
$$

Mas essa última equação se anula, pela equação da parábola, pois $y=2 \sqrt{x p}$. Isto prova a condição de que

$$
m^{\prime}\left(1-m^{2}\right)-2 m=0,
$$

o que completa a demonstração da propriedade refletora da parábola.

Assim, considere um espelho côncavo no formato de uma paraboloide de revolução em torno de seu eixo $O x$ (Figura 3.5). 


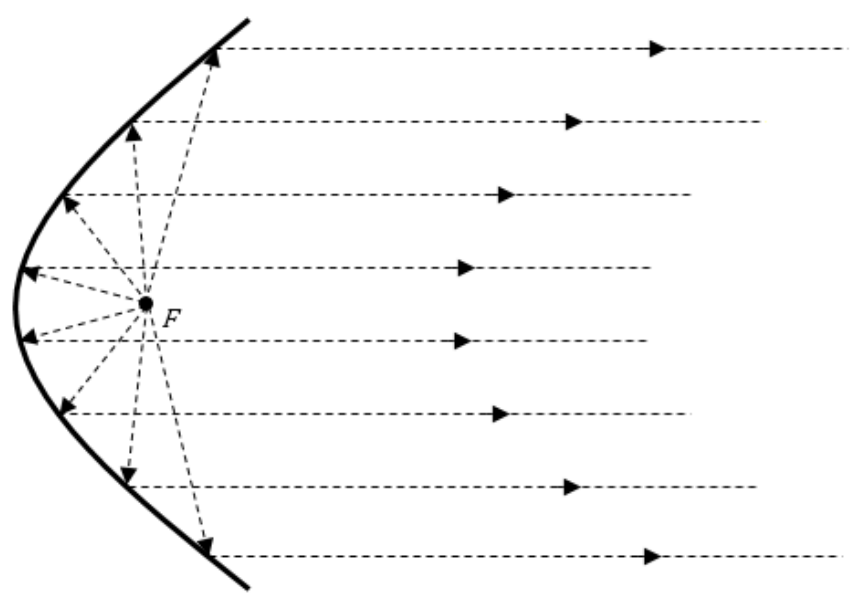

Figura 3.5: Espelho parabólico

Se uma fonte luminosa for colocada em seu foco, os raios de luz que dela partirem e incidirem no espelho, produzirão raios refletidos paralelos ao eixo $O x$. Isso nada mais é que a lei de reflexão da luz, segundo a qual os ângulos de incidência e reflexão devem ser iguais. Reciprocamente, se um feixe de raios paralelos ao eixo $O x$ incide sobre o espelho, eles se refletem, indo convergir no foco. Essas propriedades são usadas na construção de refletores e telescópios.

Uma lenda famosa sobre essa propriedade é a de que conhecendo as propriedades refletoras da parábola, Arquimedes teria tido a ideia de construir espelhos parabólicos gigantes para incendiar os barcos dos romanos quando das invasões de Siracusa. Utilizando o fato de que a concentração de energia gera calor, Arquimedes teria indicado que os raios solares, considerados paralelos chegariam aos espelhos e seriam refletidos em um único ponto, o foco. Com isso, moveriam convenientemente os espelhos de forma que o foco coincidisse com a posição do navio do inimigo, o incendiando (Figura 3.6).

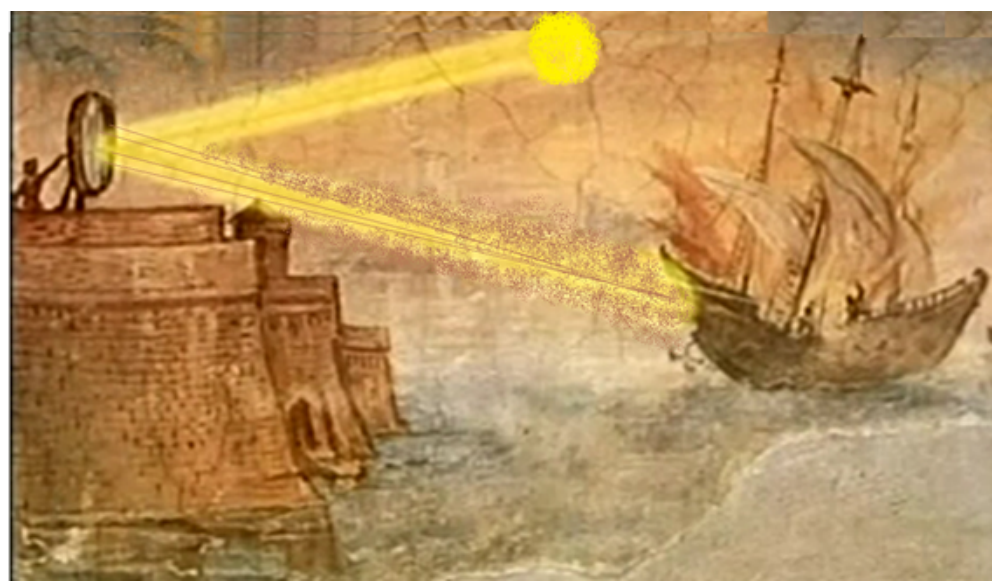

Figura 3.6: A lenda de Arquimedes 
Ainda baseando-se nas propriedades refletoras das parábolas foram desenvolvidos os projetos de construções dos faróis dos carros. A intenção na construção dos faróis é de que os feixes de luz não se dispersem para que não haja o ofuscamento da visão do motorista que vem no sentido contrário. Nos faróis dos carros encontram-se duas opções de iluminação: a luz baixa e a luz alta. A luz baixa é obtida com a lâmpada situada no foco do paraboloide, que, conforme foi demonstrado anteriormente, faz com que os feixes de luz refletidos pelo espelho parabólico do farol, saiam paralelos ao eixo de simetria da parábola, conforme figura 3.7.

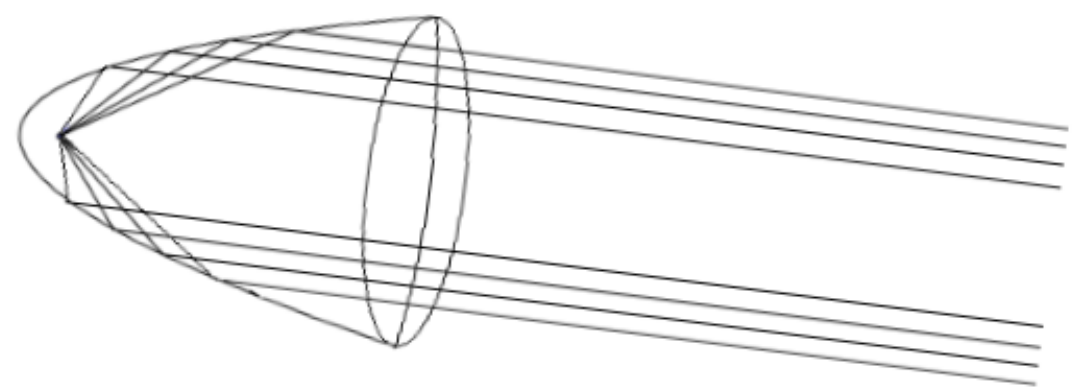

Figura 3.7: A parábola e os faróis de carros - luz baixa

Já a luz alta, é obtida com a lâmpada situada no eixo de simetria do paraboloide, porém, entre o foco e o vértice da parábola. Essa mudança na posição da luz faz com que os raios divirjam, gerando a luz alta, conforme figura 3.8. Obviamente isso contradiz a informação de que os feixes de luz não deveriam se dispersarem, porém, a regulagem da posição da luz é feita de modo que a dispersão não seja grande e ainda assim, o código de trânsito exige que seja utilizada a luz baixa ao passar por outro veículo.

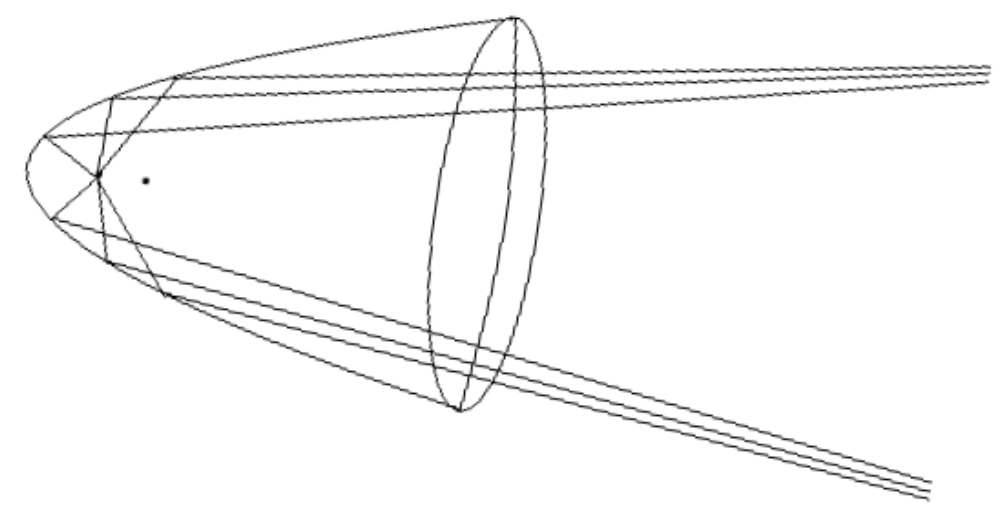

Figura 3.8: A parábola e os faróis de carros - luz alta 


\section{Prova:}

Tome a fonte luminosa em um ponto $F^{\prime} \neq F$ conforme Figura 3.9.

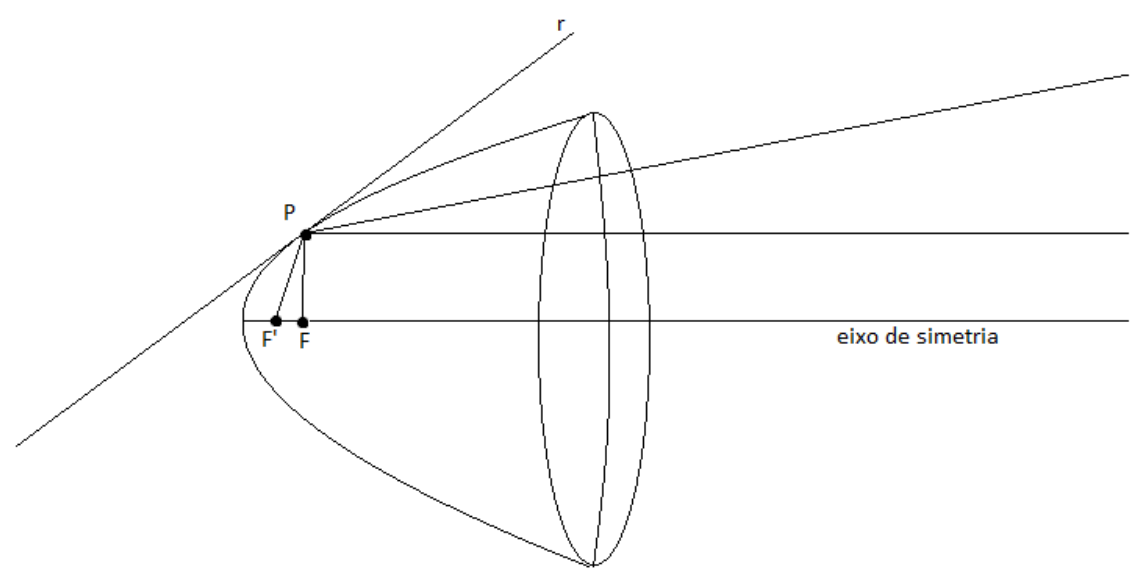

Figura 3.9: Fonte de luz entre o foco e o vértice

Seja $F^{\prime} P$ o raio emitido por essa fonte. Já foi demonstrado que se a fonte luminosa estivesse no foco $F$, o raio refletido seria paralelo ao eixo de simetria e o ângulo formado pelo raio de luz com a reta $r$, tangente com a parábola em $P$ seria congruente ao ângulo formado pelo raio refletido dessa tangente. Mas, se a fonte luminosa for colocada antes do foco $F$, ou seja, for colocada no ponto $F^{\prime}$, o ângulo formado por esse raio e a tangente em $P$ seria menor que o ângulo formado pelo raio e tal reta de acordo com as leis de reflexão. Portanto, esse raio irá divergir.

Observe que se a luz for, então colocada no eixo de simetria da parábola tem-se três possibilidades:

(I) Sobre o foco: os raios refletem paralelamente ao eixo de simetria da parábola;

(II) Entre o foco e o vértice da parábola: os raios refletidos divergem;

(III) Posterior ao foco (no sentido vértice-foco): os raios refletidos convergem para pontos sobre o eixo de simetria.

\subsection{Propriedades refletoras da hipérbole}

A hipérbole apresenta a seguinte propriedade: toda reta tangente a uma hipérbole, em um ponto $P$, é também a bissetriz do ângulo $F_{1} P F_{2}$, onde $F_{1}$ e $F_{2}$ são os focos da hipérbole (Figura 3.10). 


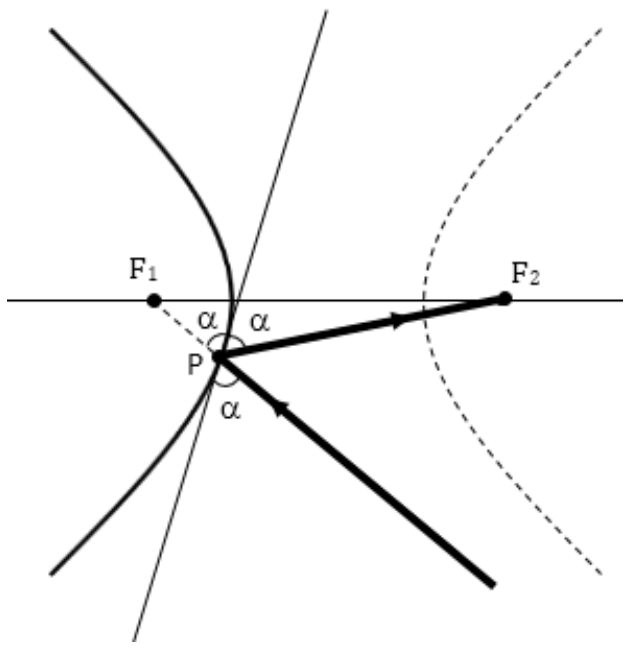

Figura 3.10: Propriedade refletora da hipérbole

Essa propriedade garante que todo raio de luz emitido na direção de um dos focos, reflete no ramo mais próximo e passa pelo outro foco, que é a propriedade refletora da hipérbole (Figura 3.11).

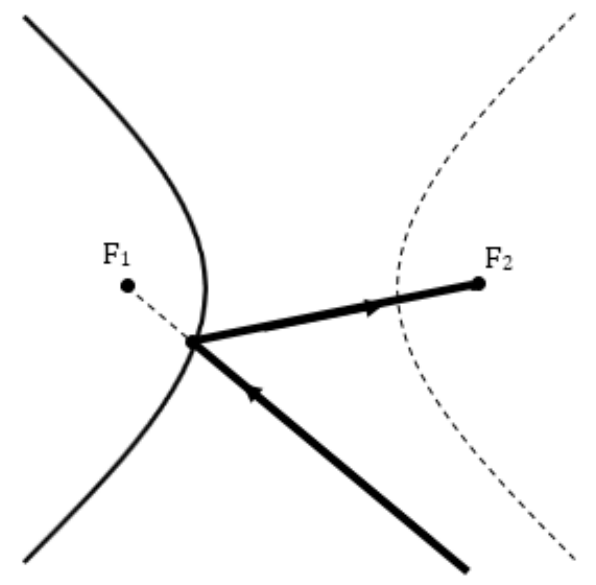

Figura 3.11: O espelho hiperbólico

\section{Demonstração}

Vamos primeiro provar que a bissetriz do ângulo $F_{1} P F_{2}$ é também tangente à hipérbole em $P$ (Figura 3.12). 


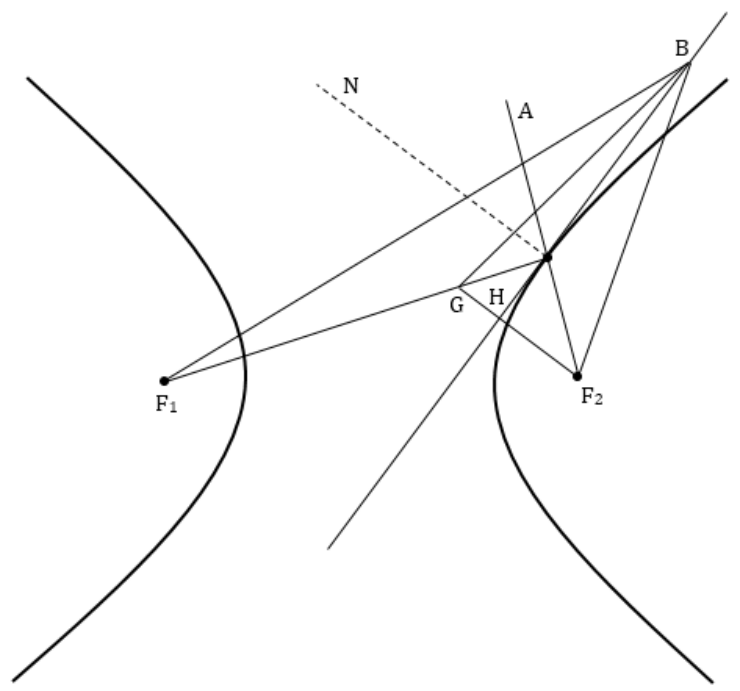

Figura 3.12: A reflexão na hipérbole

Supondo que a bissetriz e a tangente sejam a mesma reta, seja $B$ um ponto qualquer da bissetriz; $F_{2} G \perp B P \perp N P$ donde $N P$ e $G F_{2}$ são retas paralelas e o triângulo $P G F_{2}$ é isósceles de base $G F_{2}$. Como consequência, os ângulos desse triângulo em $G$ e $F_{2}$ são iguais. Mas o ângulo em $F_{2}$ e $\widehat{N P A}$ também são iguais, por serem correspondentes. Ainda, o ângulo $\widehat{F_{2} G P}$ é igual ao ângulo $\widehat{N P G}$ pois são alternos internos. Portanto, o ângulo de incidência é igual ao ângulo de reflexão. Disso e da lei de reflexão da luz, conclui-se que este último ângulo é, realmente, o ângulo de reflexão, isto é, o raio refletido passa por $F_{1}$.

Resta provar que a bissetriz $B P$ é também a tangente à hipérbole em $P$. Pela análise da Figura 3.12

$$
B F_{1}<B G+G F_{1}
$$

Então

$$
B F_{1}-B F_{2}<B G+G F_{1}-B F_{2}
$$

Mas

$$
B G=B F_{2}
$$

pois o triângulo $B G F_{2}$ é isósceles, portanto,

$$
B F_{1}-B F_{2}<G F_{1}=P F_{1}-P G=P F_{1}-P F_{2}=d
$$

o que garante que qualquer que seja $B$, tem-se que $B$ não pertence à hipérbole, concluindo assim que a reta $B P$ é tangente à hipérbole.

Foi baseando-se nessa propriedade refletora da hipérbole que Isaac Newton (1642-1727) desenvolveu a ideia do telescópio e em seguida, o astrônomo francês Cassegrain propôs 
a utilização de um espelho hiperbólico em combinação com um espelho parabólico o que gerou avanços significativos. (Figura 3.13).

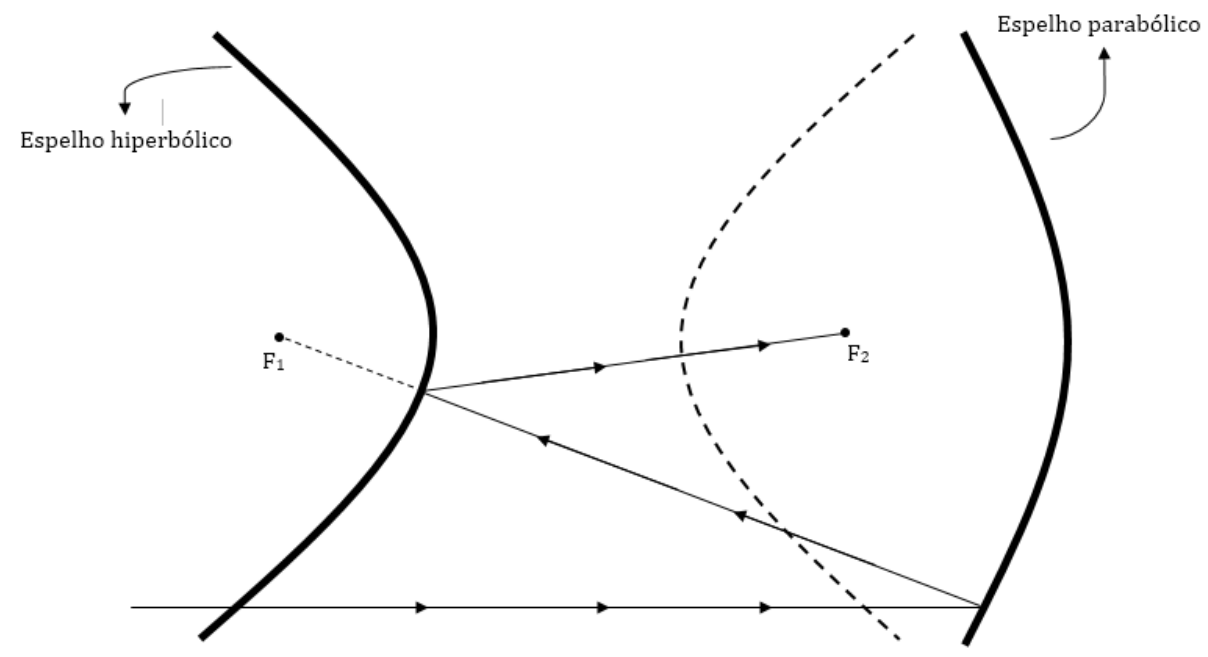

Figura 3.13: Combinação de espelhos hiperbólicos e parabólicos na confecção de telescópios

Os raios da imagem distante formam um feixe praticamente paralelos que chega ao espelho parabólico, é refletida em direção ao seu foco que coincide com o foco $F_{1}$ da hipérbole chegando ao espelho hiperbólico e sendo refletido, finalmente em seu foco $F_{2}$, onde se encontra o olho do observador no telescópio.

Essas montagens de Cassegrain somente começaram a ser utilizadas nos telescópios cerca de um século após terem sido propostas. Desde então passaram a ser largamente usadas, e hoje em dia estão presentes não apenas nos telescópios óticos, mas também nos radiotelescópios. O famoso telescópio ótico do observatório de Monte Palomar, que fica $80 \mathrm{~km}$ a nordeste de San Diego, na Califórnia, utiliza várias montagens do tipo de Cassegrain. 
Capítulo

4

Propostas de atividade para se

trabalhar as curvas elipses, hipérboles e parábolas no ensino médio

No capítulo 3 deste trabalho levantei algumas questões sobre o ensino de cônicas no Ensino Médio. Neste capítulo, pretendo apresentar algumas propostas de atividades que, ao meu ver, podem ser formas alternativas de se trabalhar o assunto Cônicas. Lançarei mão de algumas sugestões de aulas que podem ser aplicadas por professores do ensino médio com suas turmas.

\subsection{Atividade de manipulação de materiais articulados}

Uma das propostas de se trabalhar as cônicas com os alunos no Ensino Médio é fazer as construções das curvas utilizando materiais articulados que podem ser montados pelos próprios alunos. Isto pode proporcionar boas aulas nos laboratórios de Matemática. Na Revista do Professor de Matemática (RPM no 80) foi publicado um artigo com o título "Instrumentos articulados que desenham cônicas" pelos professores Lúcia Resende Pereira e Valdir Bonfim da UFU/Uberlândia-MG no qual mostram-se alguns instrumentos. No artigo, foi sugerido que os alunos construíssem os materiais. Considero que trata-se de uma excelente opção, porém devido às dificuldades que podem ser encontradas, como falta de equipamentos, laboratórios apropriados, o que é bastante comum na maioria das escolas brasileiras, minha sugestão é de que o professor já tenha as peças dos equipamentos prontas e que a atividade consista em montagem e discussão das propriedades das cônicas. 


\subsubsection{Parabológrafo: Instrumento articulado para traçar parábo- las}

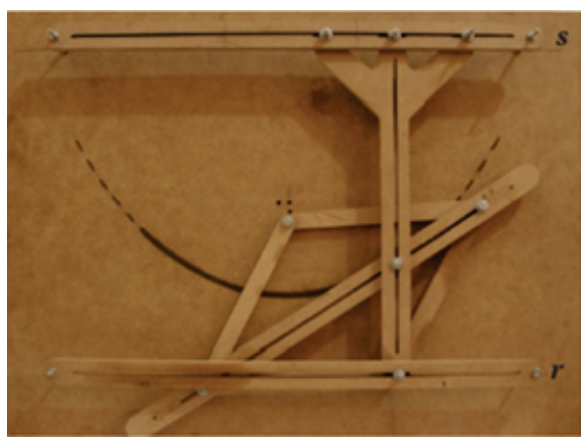

Figura 4.1: Parabológrafo

\section{Proposta de aula 1}

Esta atividade pode ser desenvolvida em grupos num laboratório de matemática. Os alunos deverão montar um instrumento denominado parabológrafo (Figura 4.1). Trata-se de um instrumento articulado utilizado para traçar parábolas. Após sua montagem os alunos devem utilizá-lo para construir parábolas e em seguida devem fazer discussões e verificações das propriedades da parábola. O professor deverá levar os pedaços de madeira já cortados nos tamanhos desejados e com os respectivos furos e a atividade pode ser desenvolvida com os alunos montando o instrumento e verificando o porquê de seu funcionamento, seguindo um roteiro pra aula.

\section{Material:}

$\checkmark 8$ pedaços de madeira já cortadas e com os respectivos furos;

$\checkmark 5$ suportes de espaçamento;

$\checkmark$ Uma base para a montagem;

$\checkmark$ Parafusos e porcas;

$\checkmark$ Ficha com orientações para a montagem do parabológrafo;

$\checkmark$ Roteiro de atividade.

Essa ficha contem algumas orientações e perguntas para direcionar os alunos a fazerem as análises desejadas pelo professor. Observação: as perguntas ou solicitações apresentadas na ficha são apenas algumas sugestões. Cabe ao professor escolher quais seriam as 
proposições que melhor se encaixariam ao seu objetivo no planejamento.

Modelo da ficha (Figura 4.2):

A figura abaixo ilustra o mecanismo do parabológrafo. Analise- o e faça o que se pede nos itens seguintes.
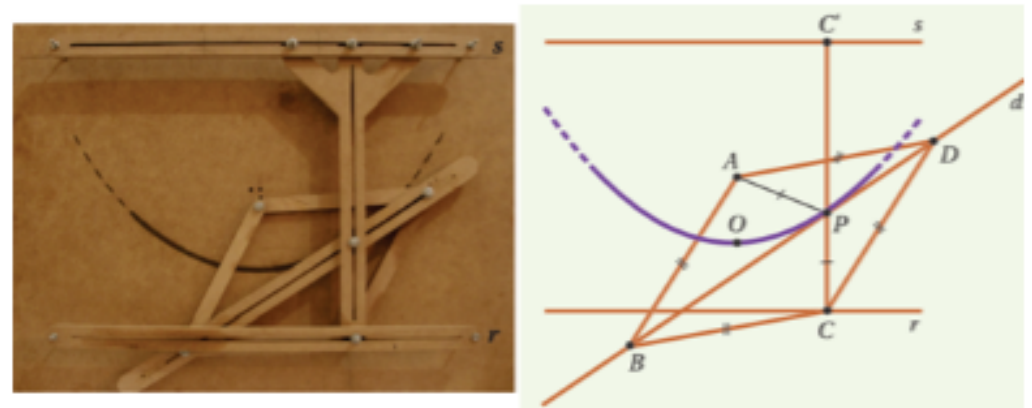

1- Pesquise na internet e escreva a definiçao de parábola como lugar geométrio.

2- Mostre que a distância entre os pontos $\mathrm{P}$ e A será sempre igual a distância entre o ponto $\mathrm{P}$ e $\mathrm{C}$.

3- No esquema apresentado do parabológrafo identifique quais pontos representam o foco e o vértice e qual é a reta diretriz.

Figura 4.2: Roteiro de atividade - parabológrafo 


\section{Justificativa do funcionamento do parabológrafo.}
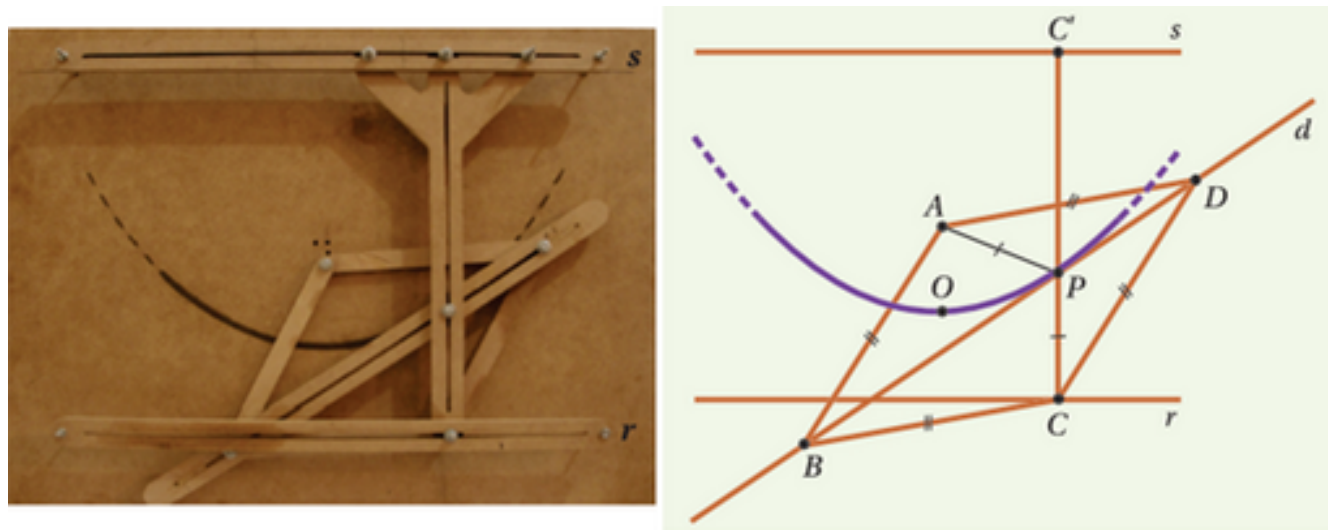

Figura 4.3: O funcionamento do parabológrafo

Na foto e no esquema (Figura 4.3), as retas $r$ e $s$ são paralelas. Os pontos $C$ e $C^{\prime}$ deslizam sobre $r$ e $s$, respectivamente, de forma que o segmento $C C^{\prime}$ seja sempre perpendicular a essas paralelas. O quadrilátero $A B C D$ é um losango articulado com $A B=B C=C D=D A$. O vértice $A$ do losango é fixo. O vértice $C$, oposto ao vértice $A$, desliza sobre $r$. Os outros dois vértices, $B$ e $D$, determinam a reta $d$, que intersecta o segmento $C C^{\prime}$ no ponto $P$. À medida que $C$ desliza sobre $r$, o ponto $P$ descreve uma parábola com foco $A$ e diretriz $r$. Conforme você verá a seguir, tal instrumento foi apropriadamente construído de tal forma que, ao se deslocar o mecanismo sobre uma reta (diretriz), o ponto $P$ (em que se acopla o lápis) percorre um "caminho" que é uma parábola. Para justificar esse processo, observe que os triângulos $P A B$ e $P C B$ são congruentes pelo caso de congruência $L A L$, já que os ângulos $A B P$ e $C B P$ são iguais. A congruência implica $P A=P C$. Assim, o ponto $P$ é equidistante de um ponto fixo $A$ e de uma reta fixa $r$, ou seja, seu lugar geométrico é a parábola de foco $A$ e diretriz $r$ [11]. 


\subsubsection{Elipsógrafo: Instrumento articulado para traçar elipses}

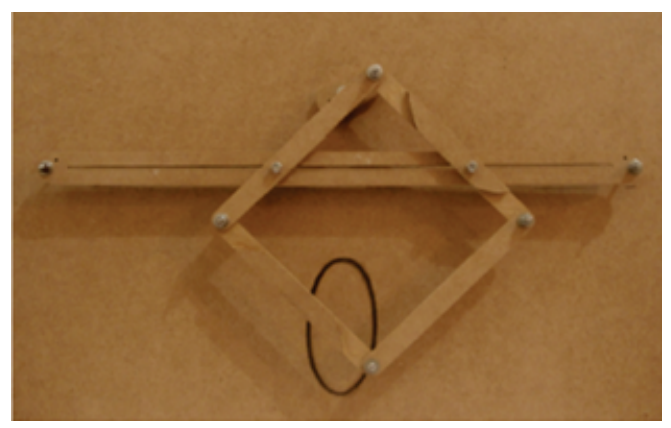

Figura 4.4: Elipsógrafo

\section{Proposta de aula 2}

Esta atividade pode ser desenvolvida em grupos num laboratório de matemática. Os alunos deverão montar um instrumento denominado elipsógrafo (Figura 4.4). Trata-se de um instrumento articulado utilizado para traçar elipses. Após sua montagem os alunos devem utilizá-lo para construir elipses e em seguida devem fazer discussões e verificações das propriedades da elipse. O professor deverá levar os pedaços de madeira já cortados nos tamanhos desejados e com os respectivos furos e a atividade pode ser desenvolvida com os alunos montando o instrumento e verificando o porquê de seu funcionamento, seguindo um roteiro pra aula.

\section{Material:}

$\checkmark 5$ pedaços de madeira já cortadas e com os respectivos furos;

$\checkmark 3$ suportes de espaçamento;

$\checkmark$ Uma base para a montagem;

$\checkmark$ Parafusos e porcas;

$\checkmark$ Ficha com orientações para a montagem do elipsógrafo;

$\checkmark$ Roteiro de atividade.

Essa ficha contem algumas orientações e perguntas para direcionar os alunos a fazerem as análises desejadas pelo professor. Observação: as perguntas ou solicitações apresentadas na ficha são apenas algumas sugestões. Cabe ao professor escolher quais seriam as proposições que melhor se encaixariam ao seu objetivo no planejamento. 
Modelo da ficha (Figura 4.5):

A figura abaixo ilustra o mecanismo do elipsógrafo. Analise-o e faça o que se pede nos itens seguintes.
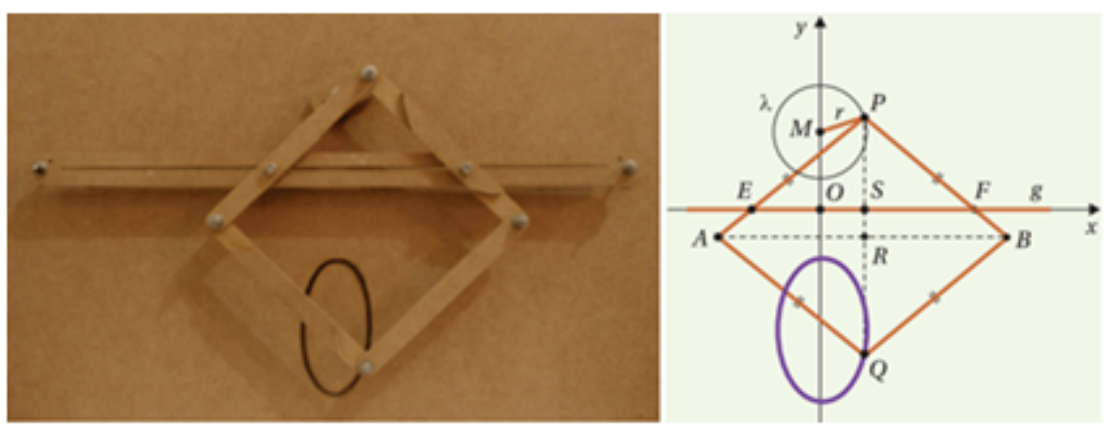

1- Pesquise na internet e escreva a definiçao de elipse como lugar geométrio.

2- Uma outra construção famosa da elipse é com a técnica do jardineiro. Pesquise sobre essa técnica e explique como utilizá-la.

3- A circunferência é uma elipse? Justifique sua resposta.

Figura 4.5: Roteiro de atividade - elipsógrafo 


\section{Justificativa do funcionamento do elipsógrafo}
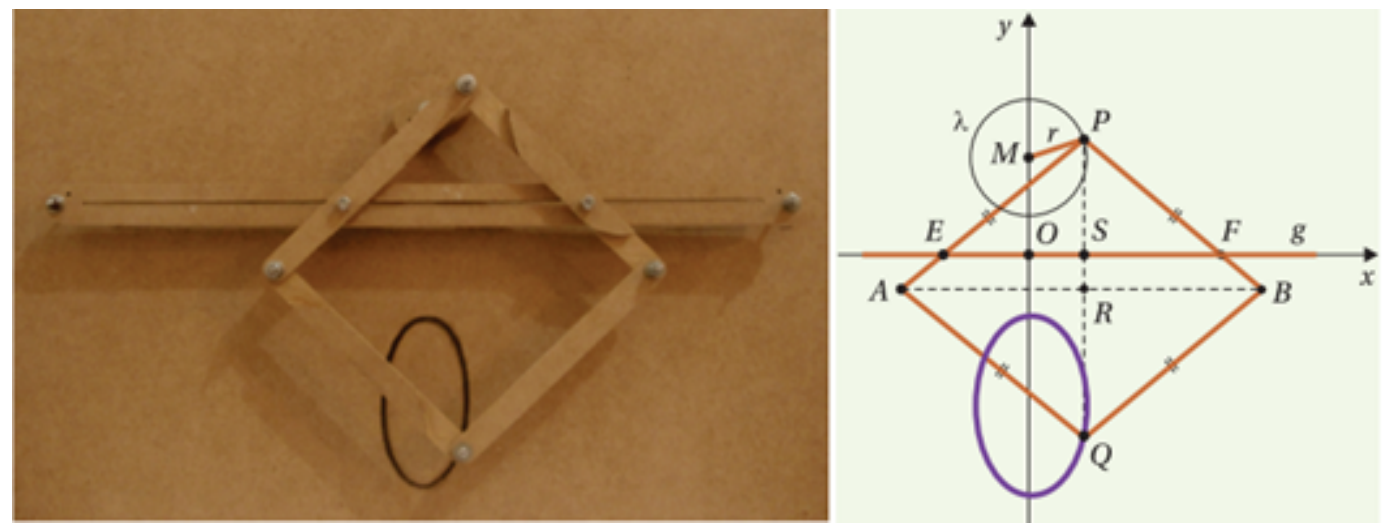

Figura 4.6: O funcionamento do elipsógrafo

Na foto e no esquema da figura 4.6, $P A Q B$ é um losango articulado de lado $l$. O vértice $P$ do losango é vinculado a um ponto fixo $M$, o qual é o centro de uma circunferência $\lambda$ de raio $P M=r$, representada, na foto, pela "tramelinha". Os pontos $E$ e $F$, fixados nos lados do losango $P A$ e $P B$, respectivamente, são escolhidos a uma mesma distância do ponto $P$ e podem deslizar sobre o trilho horizontal que aparece na foto e que, na figura, é a reta $g$. Vamos mostrar que, quando $P$ percorre a circunferência $\lambda$, os pontos $E$ e $F$ movem-se forçados a deslizar sobre o trilho $g$, o vértice $Q$ do losango (onde se acopla o lápis) descreve uma elipse, que possui um semieixo igual ao raio da circunferência $\lambda$ e o outro semieixo com comprimento dependendo da escolha dos pontos $E$ e $F$. Para justificar que a curva desenhada é uma elipse, vamos usar coordenadas. Sejam $P A=P B=Q B=Q A=l$ e $P E=P F=d$. Adotamos um referencial cartesiano com o eixo $x$ sobre a reta $g$ e o eixo $y$ perpendicular à reta $g$, passando pelo ponto $M$. Nesse sistema de coordenadas, sejam $P=(a, b)$ e $Q=(x, y)$. Traçamos os segmentos $P Q$ e $A B$, que se cortam no ponto $R$. Indicamos por $S$ o ponto de interseção da reta $g$ com o segmento $P Q$. Da semelhança entre os triângulos $P S F$ e $P R B$, temos:

$$
\frac{d}{b}=\frac{P F}{P S}=\frac{P B}{P R}=\frac{l}{P R},
$$

que implica

$$
P R=\frac{l b}{d}
$$

Vamos agora determinar a medida do segmento $Q S$ para obter a ordenada do ponto $Q$ :

$$
Q S=R S+Q R \Rightarrow
$$




$$
\begin{gathered}
Q S=P R-P S+Q R \Rightarrow \\
Q S=P R-P S+P R \Rightarrow \\
Q S=2 P R-P S \Rightarrow \\
Q S=2\left(\frac{l b}{d}\right)-b \Rightarrow \\
Q S=\frac{2 l b-b d}{d} \Rightarrow \\
Q S=b \frac{2 l-d}{d} .
\end{gathered}
$$

Faremos

$$
\frac{2 l-d}{d}=c
$$

uma constante que depende das dimensões do instrumento e da posição dos pontos fixos $E$ e $F$. Assim, $Q S=c b$. Como os pontos $P$ e $Q$ têm mesma abscissa, temos $x=a$. A ordenada, $y$, de $Q$ no sistema escolhido é $-Q S=-c b$. A distância do ponto $P=(a, b)$ ao ponto $M=(0, h)$, centro da circunferência $\lambda$, é $r$, o seu raio. Portanto,

$$
a^{2}+(b-h)^{2}=r^{2}
$$

Fazendo a substituição

$$
a=x
$$

$\mathrm{e}$

$$
b=-\frac{y}{c},
$$

obtemos

$$
x^{2}+\left(-\frac{y}{c}-h\right)^{2}=r^{2}
$$

$\mathrm{Ou}$

$$
\frac{x^{2}}{r^{2}}+\frac{(y+c h)^{2}}{c^{2} r^{2}}=1 .
$$

Podemos concluir daí que o ponto $Q$ descreve uma elipse que possui um semieixo igual ao raio da circunferência e outro cujo comprimento depende das medidas do instrumento e da escolha dos pontos $E$ e $F$ [11]. 


\subsubsection{Hiperbológrafo: Instrumento articulado para traçar hipér- boles}

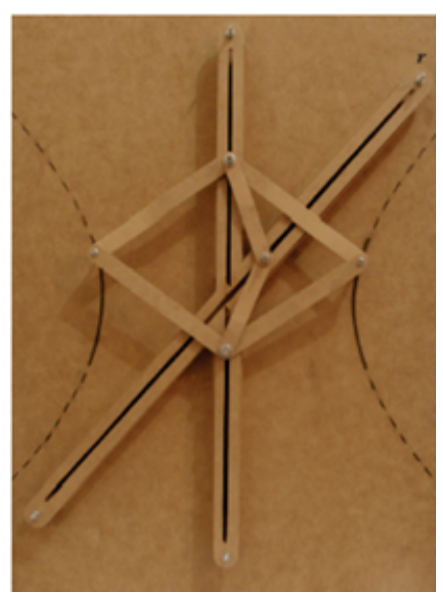

Figura 4.7: Hiperbológrafo

\section{Proposta de aula 3}

Esta atividade pode ser desenvolvida em grupos num laboratório de matemática. Os alunos deverão montar um instrumento denominado hiperbológrafo (Figura 4.7). Trata-se de um instrumento articulado utilizado para traçar hipérboles. Após sua montagem os alunos devem utilizá-lo para construir hipérboles e em seguida devem fazer discussões e verificações das propriedades da hipérbole. O professor deverá levar os pedaços de madeira já cortados nos tamanhos desejados e com os respectivos furos e a atividade pode ser desenvolvida com os alunos montando o instrumento e verificando o porquê de seu funcionamento, seguindo um roteiro pra aula.

\section{Material:}

$\checkmark 8$ pedaços de madeira já cortadas e com os respectivos furos;

$\checkmark 4$ suportes de espaçamento;

$\checkmark$ Uma base para a montagem;

$\checkmark$ Parafusos e porcas;

$\checkmark$ Ficha com orientações para a montagem do parabológrafo;

$\checkmark$ Roteiro de atividade. 
Essa ficha contem algumas orientações e perguntas para direcionar os alunos a fazerem as análises desejadas pelo professor. Observação: as perguntas ou solicitações apresentadas na ficha são apenas algumas sugestões. Cabe ao professor escolher quais seriam as proposições que melhor se encaixariam ao seu objetivo no planejamento.

Modelo da ficha (Figura 4.8):

A figura abaixo ilustra o mecanismo do hiperbológrafo. Analise-o e faça o que se pede nos itens seguintes.

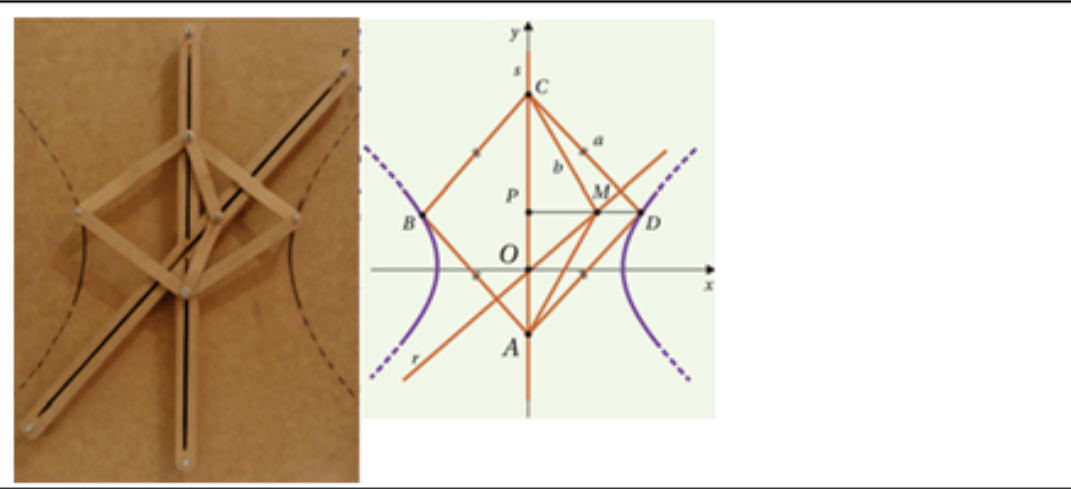

1-Pesquise na internet a definição de hipérbole como lugar geométrico.

2- Pesquise sobre seções cônicas e explique o porquê da curva hipérbole ter dois ramos.

3- Explique o que é uma hipérbole equilátera.

Figura 4.8: Roteiro de atividade - hiperbológrafo 


\section{Justificativa do funcionamento do hiperbológrafo.}

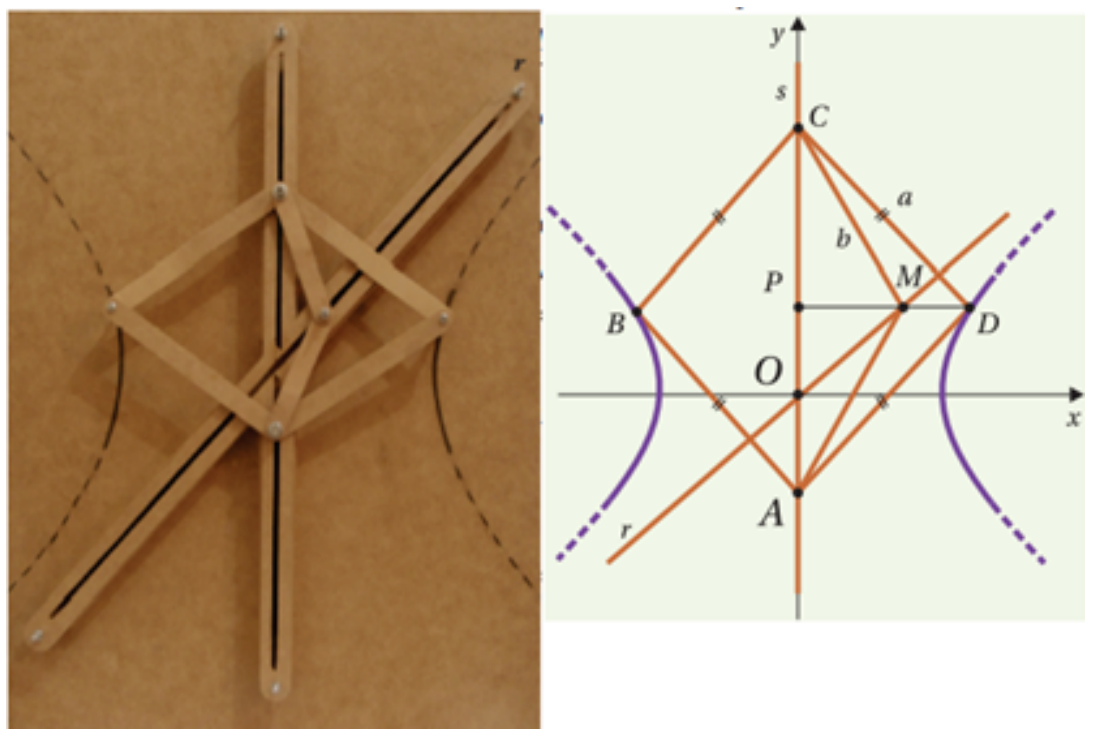

Figura 4.9: O funcionamento do hiperbológrafo

Na foto e no esquema (Figura 4.9), $A B C D$ é um losango articulado de lado a com os vértices $A$ e $C$ vinculados a um trilho vertical $s$. O ponto $M$, tal que

$$
C M=A M=b,
$$

sendo $b<a$, pode se movimentar sobre o trilho inclinado $r$. Vamos mostrar que, quando o ponto $M$ percorre a reta $r$, os pontos $A$ e $C$ deslizam sobre a reta $s$ e os pontos $B$ e $D$ (acoplados com pontas de lápis) descrevem os dois arcos de uma hipérbole.

Seja $O$ o ponto de interseção das retas $r$ e $s$. Fixado um referencial cartesiano com origem $O$ e o eixo $y$ coincidente com a reta $s$, sejam $M=(m, n)$ o ponto que percorre a reta $r$ e $D=(x, y)$ o ponto que percorrerá uma parte do ramo direito da hipérbole. Na figura, $C D=a, C M=b, P M=m$ e $P D=x$. Aplicando o teorema de Pitágoras aos triângulos $C P M$ e $C P D$, obtemos

$$
(C M)^{2}-(P M)^{2}=(C D)^{2}-(P D)^{2}
$$

Daí, segue que

$$
b^{2}-m^{2}=a^{2}-x^{2}
$$

ou seja,

$$
m^{2}=x^{2}-\left(a^{2}-b^{2}\right)
$$

Fazendo $a^{2}-b^{2}=c^{2}$, ficamos com $m^{2}=x^{2}-c^{2}$. 
A reta $r$ tem equação da forma $y=k x$ e, como o ponto $M=(m, n)$ pertence a essa reta, temos $n=k m$, ou, ainda, $n^{2}=k^{2} m^{2}$. Como os pontos $M$ e $D$ têm mesma ordenada, faremos as substituições: $m^{2}=x^{2}-c^{2}$ e $n=y$. Ficamos com

$$
y^{2}=k^{2}\left(x^{2}-c^{2}\right)
$$

$\mathrm{Ou}$

$$
\frac{x^{2}}{c^{2}}-\frac{y^{2}}{(k c)^{2}}=1
$$

que é a equação de uma hipérbole.

Observe que, como $B$ é simétrico de $D$ em relação a $O$, quando $D$ percorre o ramo direito da hipérbole, $B$ percorre o ramo esquerdo. Ainda, uma das assíntotas dessa hipérbole é a reta

$$
y=\frac{k c}{c} x=k x
$$

que é a reta $r$ [11].

É natural e razoável acreditar que, numa aula onde se manipulem estes equipamentos articulados, os alunos possam compreender melhor os conceitos e propriedades das curvas elipse, hipérbole e parábola. O fato de manipularem as estruturas ajuda a fixar o aprendizado não ficando somente nos conceitos analíticos.

\subsection{Atividade de utilização de sombras para observações das seções cônicas}

\section{Proposta de aula 4}

Nesta atividade a proposta é de se apresentar aos alunos um texto muito interessante que foi publicado na Revista do professor de Matemática (RPM n ${ }^{\circ} 59$ ) por José Paulo Carneiro. A ideia discutida no texto é de se utilizar de um abajur comum para mostrar a formação da hipérbole com suas sombras projetadas na parede. O texto é apresentado a seguir [10]. 


\section{TEXTO}

\section{A SOMBRA DO MEU ABAJUR}

A fotografia abaixo (Figura 4.10) reproduz o abajur do meu quarto e a sombra que ele projeta na parede. Que curvas são essas?

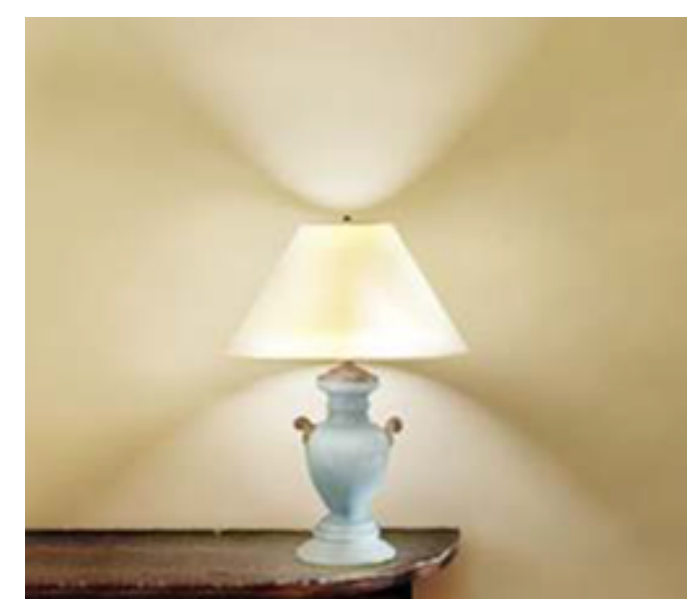

Figura 4.10: Abajur

A cúpula do abajur é um tronco de cone, com altura $h$ e raios das bases $R$ e $r$. A lâmpada é centralizada, de modo a ficar no eixo do tronco de cone. Para simplificar, podemos imaginar a lâmpada concentrada em um ponto, situado a uma distância $b$ da base inferior e a uma distância $c$ da base superior do tronco, sendo $b+c=h$ (ver Figura 4.11).

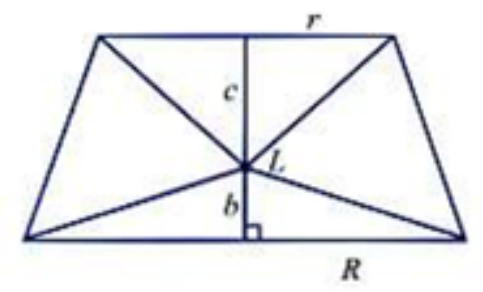

Figura 4.11: Esquema do abajur

A função da cúpula é barrar uma parte dos raios de luz, evitando que a luz atinja diretamente à vista. Os raios de luz que escapam dessa barragem formam um par de cones, ambos com vértice na lâmpada (ver Figura 4.12). Devemos imaginar esses cones prolongados para além das bases da cúpula, um para cima e outro para baixo. 


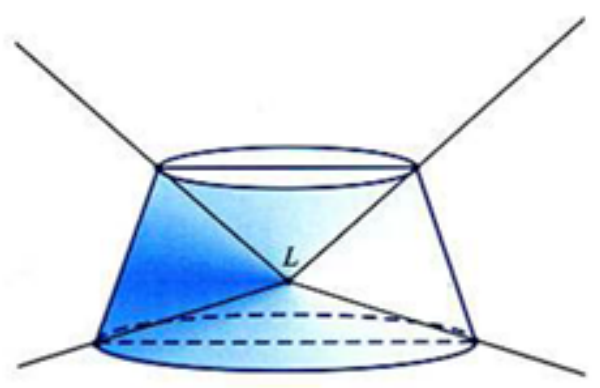

Figura 4.12: Cúpula do abajur

Para descobrir a natureza da sombra do abajur, vamos cuidar primeiro da parte superior da sombra, que é a interseção da parede com o cone de luz superior. Esse cone fica caracterizado pelo ângulo $\theta$ da Figura 4.13, que define sua "abertura" e é tal que:

$$
m=\tan \theta=\frac{r}{c}
$$

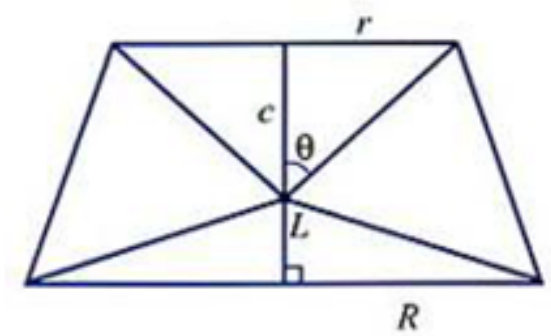

Figura 4.13: A abertura da iluminação no abajur

Criemos um sistema de coordenadas em três dimensões $O X Y Z$, de modo que a origem $O$ do sistema esteja sobre a lâmpada (concebida como um ponto) e o eixo do cone coincida com o semieixo positivo $O Z$, como na Figura 4.14.

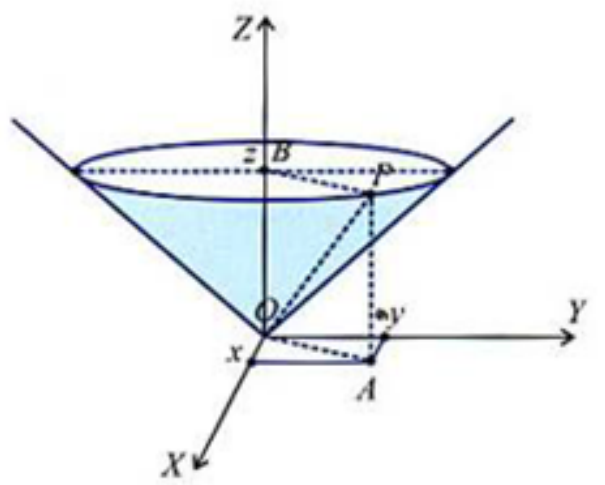

Figura 4.14: O esquema do abajur no sistema de coordenadas em três dimensões 
Nessa figura, vemos que um ponto genérico $P=(x, y, z)$ pertence à superfície do cone se, e só se, enquanto ele distar $z=A P$ do plano $X O Y$, sua distância $P B$ ao eixo permanecer igual a $O A=\sqrt{x^{2}+y^{2}}$. Porém, a Figura 4.15, vista no plano $A O B$, mostra que: $\frac{P B}{P A}=\tan \theta=m$, ou seja: $P B=m P A=m z$. Logo, a equação do cone é:

$$
m z=\sqrt{x^{2}+y^{2}}
$$

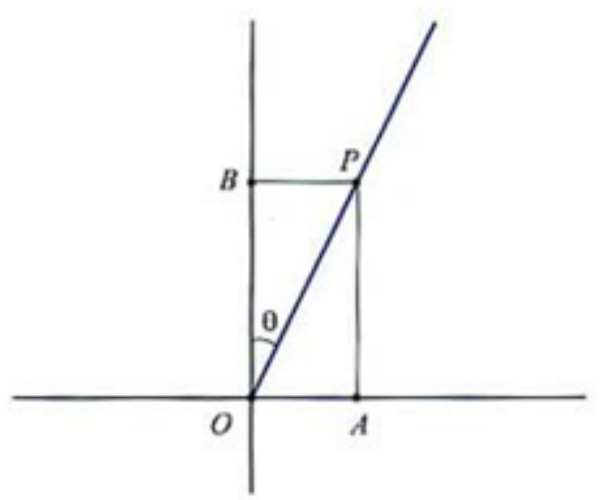

Figura 4.15: Visão do esquema do abajur no plano $A O B$

A parede é um plano paralelo ao eixo do cone. Podemos ajustar os eixos $O X$ e $O Y$ de modo que o plano $X O Z$ fique paralelo à parede. Nesse caso, a parede tem equação $y=d$, onde $d$ é a distância da lâmpada à parede. Finalmente, a curva que procuramos é a interseção do cone de equação $m z=\sqrt{x^{2}+y^{2}}$ com o plano de equação $y=d$, isto é, o conjunto dos pontos $(x, y, z)$ que são soluções do sistema:

$$
\left\{\begin{array}{l}
m z=\sqrt{x^{2}+y^{2}} \\
y=d
\end{array}\right.
$$

Esse sistema obviamente é equivalente ao sistema:

$$
\left\{\begin{array}{l}
z=\frac{c}{r} \sqrt{x^{2}+y^{2}} \\
y=d
\end{array},\right.
$$

e, se olharmos esses pontos no plano $y=d$, poderemos ficar somente com a equação $m z=\sqrt{x^{2}+d^{2}}$ que é a equação dessa curva plana nesse plano. Lembrando que $m=\frac{r}{c}$, essa equação fica:

$$
z=\frac{c}{r} \sqrt{x^{2}+d^{2}}
$$

Para o abajur do meu quarto, essas dimensões são, aproximadamente: $r=10 \mathrm{~cm}$, $R=25 \mathrm{~cm}, b=10 \mathrm{~cm}, c=20 \mathrm{~cm}$ e (quando o abajur está no seu lugar mais usual) 
$d=40 \mathrm{~cm}$.

Nesse caso, as equações da sombra são, em centímetros: $z=2 \sqrt{x^{2}+1600}$ e $z=$ $-0,4 \sqrt{x^{2}+1600}$. A figura 4.16 mostra esses gráficos obtidos por um programa de computador.

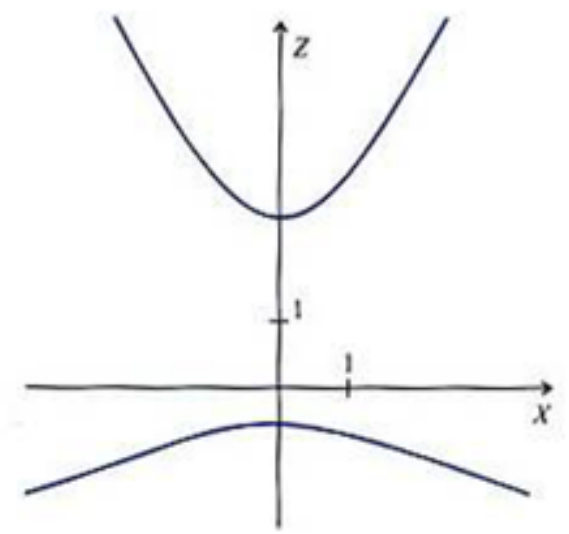

Figura 4.16: Representações gráficas das equações $z=2 \sqrt{x^{2}+1600}$ e $z=$ $-0,4 \sqrt{x^{2}+1600}$

Essas curvas que obtivemos são uma novidade ou será que já as vimos no ensino médio? Na verdade, elas são velhas conhecidas. A sombra superior tem equação

$$
z=\frac{c}{r} \sqrt{x^{2}+d^{2}}
$$

Elevando essa equação ao quadrado e manipulando, obtemos:

$$
\frac{z^{2}}{\left(\frac{c d}{r}\right)^{2}}-\frac{x^{2}}{d^{2}}=1,
$$

que é a equação de uma hipérbole com centro na origem do plano $X Z$, eixo transverso sobre o eixo $Z$, de comprimento, e eixo não transverso sobre o eixo $X$, de comprimento $2 d$.

Como a equação

$$
z=\frac{c}{r} \sqrt{x^{2}+d^{2}}
$$

é equivalente ao sistema

$$
\left\{\begin{array}{l}
\frac{z^{2}}{\left(\frac{c d}{r}\right)^{2}}-\frac{x^{2}}{d^{2}}=1 \\
z>0
\end{array},\right.
$$

vê-se que a sombra superior é o ramo positivo dessa hipérbole. Analogamente, a 
sombra inferior é o ramo negativo da hipérbole de equação:

$$
\frac{z^{2}}{\left(\frac{b d}{R}\right)^{2}}-\frac{x^{2}}{d^{2}}=1 .
$$

É interessante observar que, quando a lâmpada se situa exatamente no encontro das diagonais do trapézio da figura 4.11, então,

$$
\frac{c}{r}=\frac{b}{R}
$$

de modo que a sombra superior e a sombra inferior são os dois ramos de uma mesma hipérbole. O leitor pode verificar também que, se o abajur for cilíndrico, as duas partes da sombra serão também os dois ramos de uma mesma hipérbole. Mais ainda: se o cilindro for equilátero (altura igual ao diâmetro da base) e a lâmpada estiver centralizada, a resultante hipérbole será equilátera (eixos transverso e não transverso de mesmo comprimento).

A sugestão é de que seja feita a leitura do texto junto à turma fazendo uma discussão das explicações que são dadas no texto. Entendo que trata-se de uma atividade direcionada aos alunos do $3^{\circ}$ ano do ensino médio, pois exige-se um pouco mais de maturidade para seu melhor entendimento.

No último parágrafo do texto o autor faz uma observação de que se a lâmpada ficasse situada no encontro das diagonais do trapézio a sombra superior e a sombra inferior seriam os dois ramos de uma mesma hipérbole. Como atividade para os alunos seria interessante propor que tentassem fazer essa verificação. Observe que tendo em mãos a explicação do texto, fica fácil fazer tal verificação.

\section{Verificação}

Ficando a lâmpada localizada na interseção das diagonais do trapézio os segmentos $b$ e $c$ seriam as alturas de dois triângulos semelhantes (Figura 4.17). Pelas medidas apresentadas no textos tem-se $b+c=30$ e pela semelhança dos triângulos tem-se

$$
\frac{c}{10}=\frac{b}{25}
$$

Resolvendo o sistema composto por essas duas equações obtém-se

$$
b=\frac{150}{7}
$$


e

$$
c=\frac{60}{7}
$$

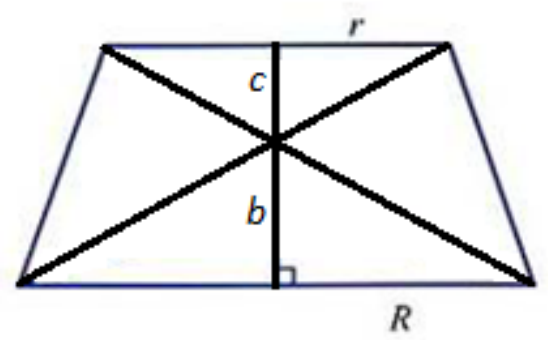

Figura 4.17: A lâmpada do abajur na interseção das diagonais do trapézio

Como a equação da curva plana na parte superior é dada por

$$
z=\frac{c}{r} \sqrt{x^{2}+d^{2}}
$$

e na parte inferior é dada por

$$
z=-\frac{b}{R} \sqrt{x^{2}+d^{2}}
$$

fazendo as devidas substituições tem-se que as equações das sombras são

$$
z=\frac{6}{7} \sqrt{x^{2}+1600}
$$

e

$$
z=-\frac{6}{7} \sqrt{x^{2}+1600}
$$

o que comprova que são os dois ramos da mesma hipérbole.

Ele observa também que se o abajur fosse cilíndrico, as curvas formadas ainda seriam os dois ramos de uma mesma hipérbole; e que se o cilindro fosse equilátero, a hipérbole formada seria também equilátera. O professor pode propor, também, como atividade para os alunos, essas verificação. Como num cilindro equilátero os eixos transverso e não transverso têm a mesma medida, basta mostrar que

$$
r=R=c=b,
$$

o que é óbvio no cilindro equilátero. 


\subsection{Atividade com cortes em cones de isopor para visu- alizações das seções cônicas}

\section{Proposta de aula 5}

Como as cônicas são curvas obtidas pelas seções planas feitas em cone, diferenciando elipses, parábolas e hipérboles apenas pelo ângulo de inclinação, nada mais natural do que desenvolver atividades onde os alunos possam verificar esses fatos compreendendo na prática o que eles lêem nos livros. A proposta é de que o professor providencie peças de isopor no formato cônico. Essas peças são facilmente encontradas em lojas que vendem artigos para festas como os conhecidos armarinhos (Figura 4.18). Um plano pode não ser paralelo a qualquer geratriz do cone, paralelo a apenas uma geratriz, ou paralelo a exatamente duas geratrizes do cone. Essas são as únicas três possibilidades e cada uma delas gera uma das cônicas. Essas características podem ser verificadas com esta atividade lúdica, porém de grande importância.

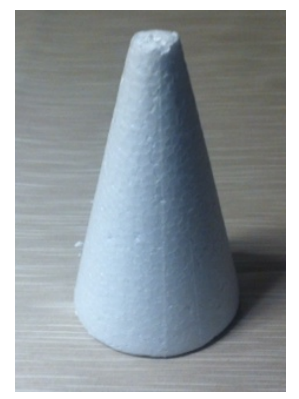

Figura 4.18: Cone de isopor

Em posse dessas peças, os alunos deverão fazer cortes utilizando uma faca de serra, variando a inclinação da faca e observarem o surgimento das cônicas.

I. Corte perpendicular ao eixo de simetria do cone (Figura 4.19).

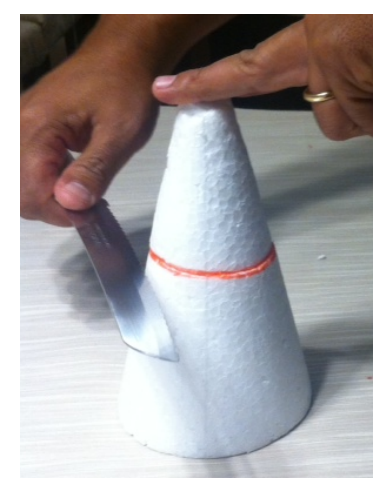

Figura 4.19: Corte gerador da circunferência 
O aluno poderá observar que, no caso do corte perpendicular ao eixo de simetria, a curva gerada é uma circunferência, que é um caso especial da elipse, pois o plano do corte não é paralelo a nenhuma das geratrizes do cone (Figura4.20).

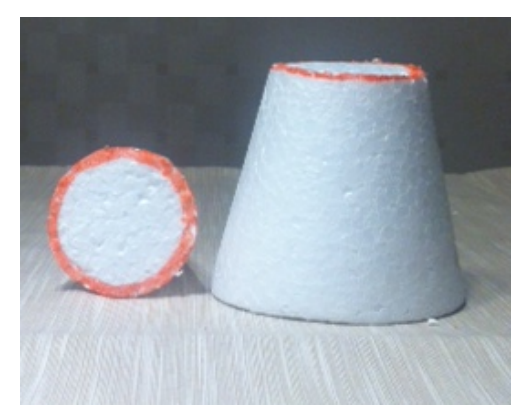

Figura 4.20: Visualização da circunferência

II. Corte inclinado, mas não paralelo a qualquer geratriz do cone (Figura 4.21).

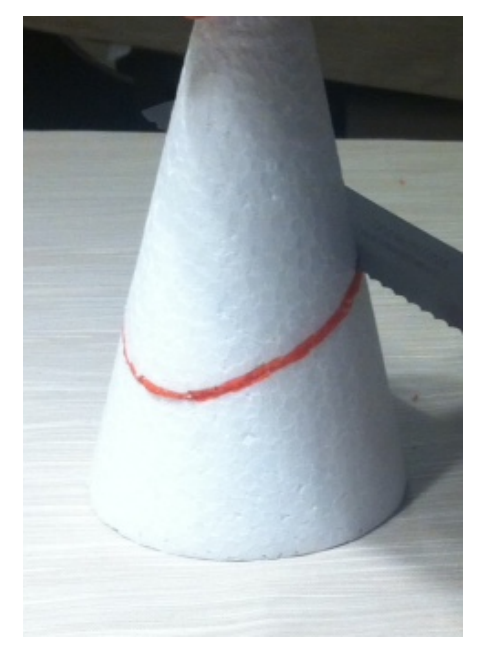

Figura 4.21: Corte gerador da elipse

O aluno deverá observar que, se o corte não é paralelo a qualquer geratriz do cone, então a curva gerada é uma elipse (Figura 4.22).

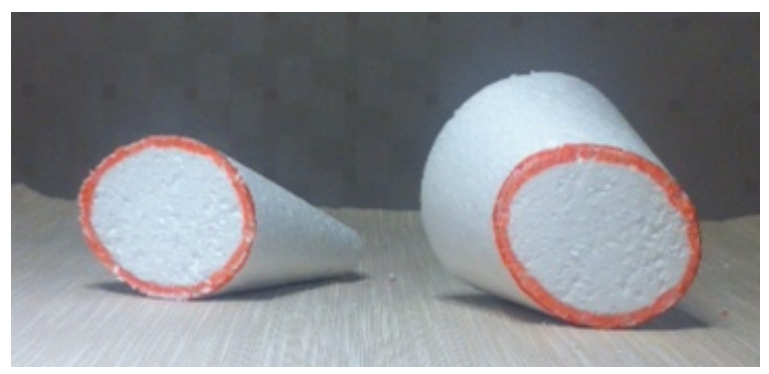

Figura 4.22: Visualização da elipse 
III. Corte paralelo a exatamente uma geratriz do cone (Figura 4.23).

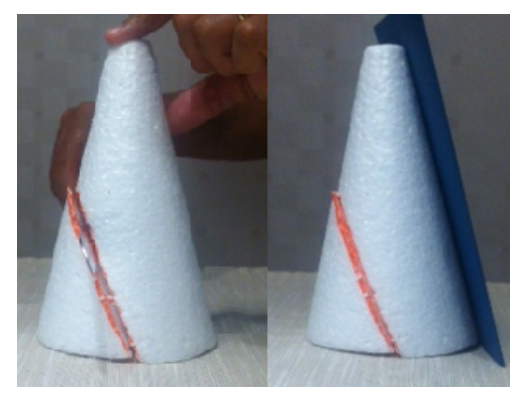

Figura 4.23: corte gerador da parábola

Manipulando as peças obtidas o aluno poderá observar que a curva gerada pelo corte paralelo a uma das geratrizes do cone é uma parábola (Figura 4.24).

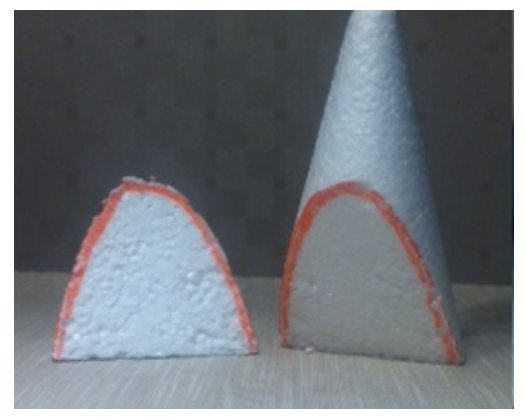

Figura 4.24: Visualização da parábola

IV. Corte paralelo a duas geratrizes do cone (Figura 4.25).

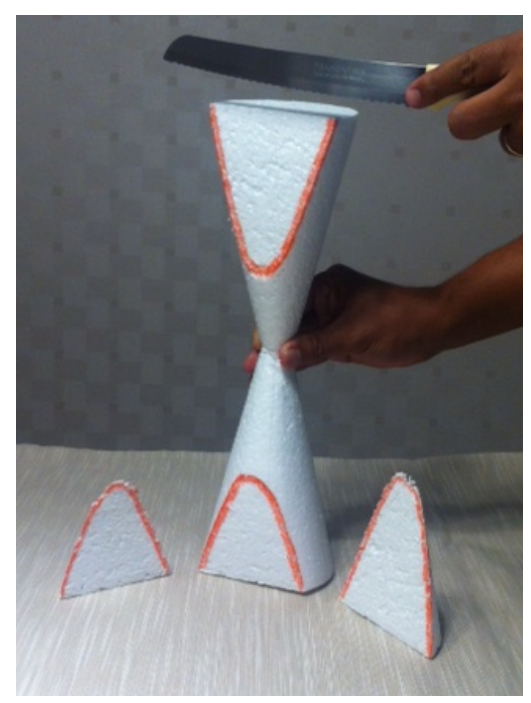

Figura 4.25: Corte gerador da hipérbole 
O aluno deverá perceber que neste último caso, a inclinação do corte fica paralela a duas geratrizes e que por este motivo cortaria também o cone colocado de modo que simulassem o cone de folhas duplas, gerando assim, os dois ramos da hipérbole.

\subsection{Atividade de construção da mesa de sinuca elíptica}

\section{Proposta de aula 6}

Nesta atividade, o objetivo é de verificar a propriedade reflexiva da elipse, que supostamente já foi trabalhada com os alunos.

A ideia é de construir em um laboratório, caso a escola tenha, uma mesa de sinuca no formato elíptico. Os alunos deverão verificar por meio de experimentos que uma bola tacada a partir de um dos focos para qualquer direção da elipse, cairá no buraco, que deverá ser feito exatamente no outro foco da elipse. Trata-se de uma atividade lúdica, porém de grande importância para que se desperte a curiosidade e o interesse dos alunos pelo tema.

\section{Material:}

$\checkmark 3$ placas de madeira de $120 \mathrm{~cm} \times 80 \mathrm{~cm}$;

$\checkmark 4$ pedaços de madeira de $80 \mathrm{~cm}$ de comprimento para os pés;

$\checkmark 2$ pedaços de madeira de $80 \mathrm{~cm}$ e 2 pedaços, de $120 \mathrm{~cm}$ para as bordas laterais;

$\checkmark 1$ tecido para forrar a mesa de $130 \mathrm{~cm} \times 90 \mathrm{~cm}$;

$\checkmark 1$ tira de borracha de $275,81 \mathrm{~cm}$ de comprimento para fazer as tabelas;

$\checkmark 1$ cesta para a caçapa;

$\checkmark 16$ parafusos com porcas;

$\checkmark$ Grampos.

\section{Roteiro para a confecção da mesa}

$\checkmark$ Faça um recorte em duas placas de madeira no formato elíptico desejado. Para nosso exemplo, as dimensões sugeriras encontram-se na figura 4.26. 


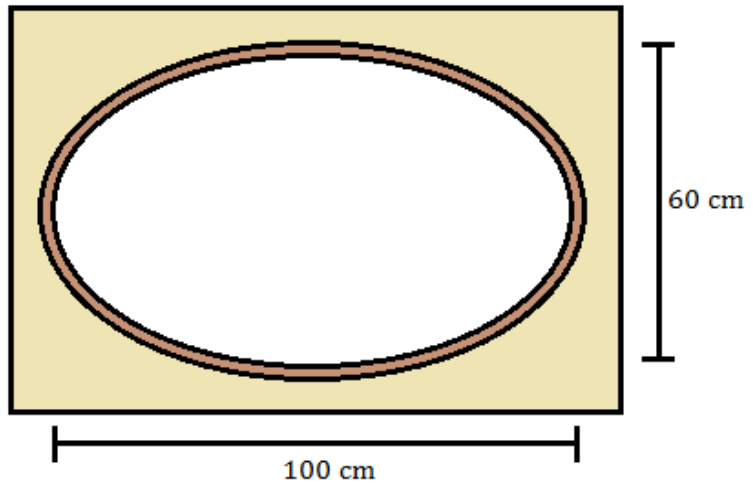

Figura 4.26: Dimensões da elipse

Observação: muita atenção nesta etapa, pois essas dimensões são da parte interna da elipse e devem ser obedecidas após a fixação da borracha nas laterais. Para isso faça a marcação utilizando a técnica do jardineiro, conforme figura 4.27.

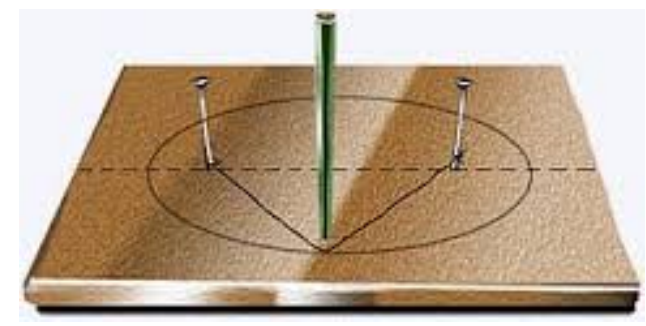

Figura 4.27: Elipse do jardineiro

$\checkmark$ Faça os furos de fixação dos pés nas bordas laterais da mesa;

$\checkmark$ Forre a placa de madeira sem recorte com o tecido, prendendo com os grampos;

$\checkmark$ Monte as peças, fixando-as com parafusos, de acordo com o esquema indicado na figura 4.28 .

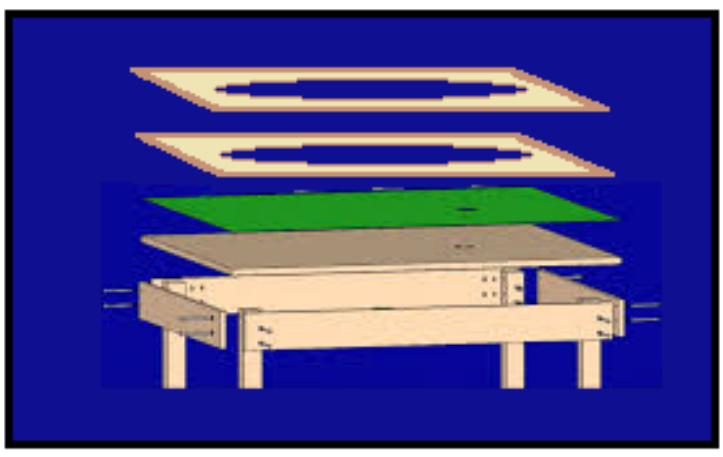

Figura 4.28: Esquema de montagem da mesa 
$\checkmark$ Faça o furo da caçapa num dos focos e prenda a cestinha da bola;

$\checkmark$ Faça a marcação do ponto de tacada da bola com um pincel na posição do outro foco.

O resultado final deverá ser conforme a figura 4.29.

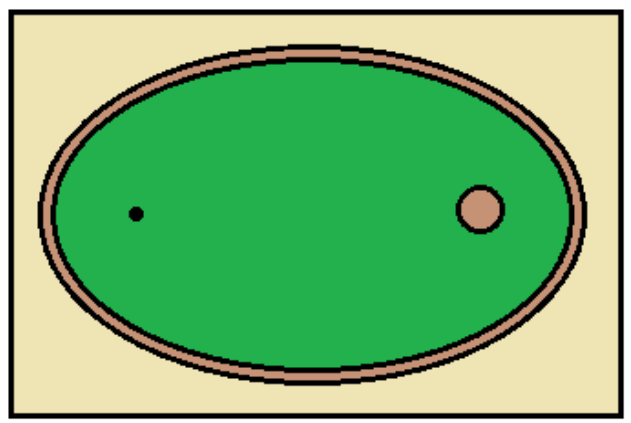

Figura 4.29: Visão superior da mesa

O taco, a bola e a cesta da caçapa podem ser encontrados em qualquer loja especializada no jogo.

O leitor interessado poderá encontrar vídeos na internet exemplificando o experimento. A figura 4.30 foi obtida no site: https://www.youtube.com/watch? $v=N G i M w 4 d I 8 f k$.

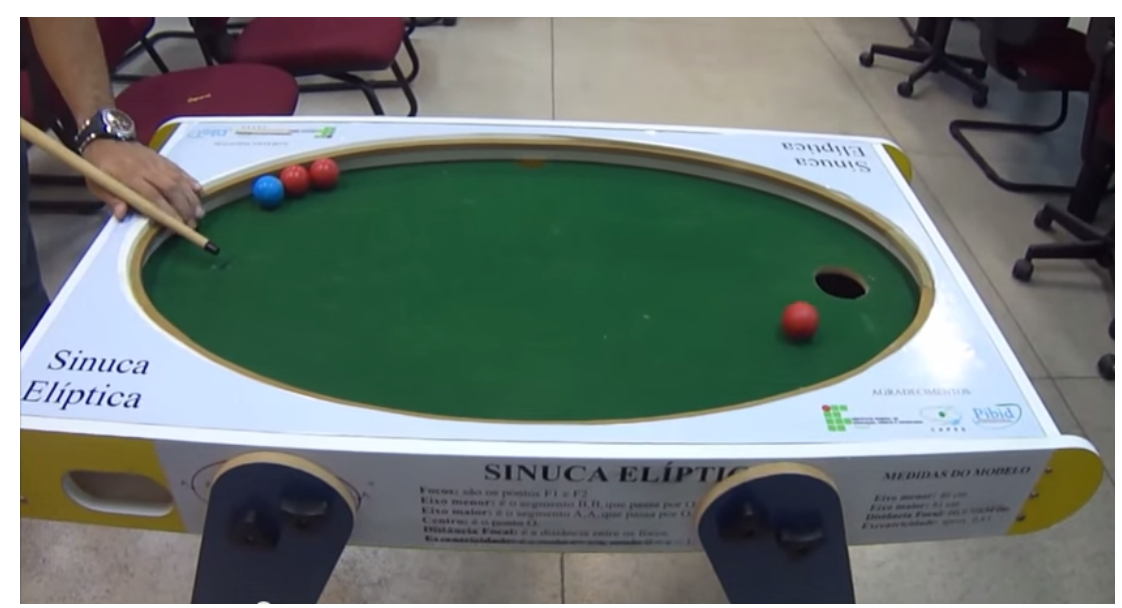

Figura 4.30: Mesa de sinuca elíptica 


\section{Considerações Finais}

As seções cônicas são, sem dúvida, curvas fascinantes. O estudo dessas curvas bem como de suas propriedades refletoras nos leva a conhecer o mundo encantador da Matemática. Neste trabalho fizemos abordagens sobre o tema e apresentamos ao leitor algumas de suas aplicações em construções de equipamentos que são de grande utilidade a humanidade. Com este trabalho espero que possa ter colaborado para que a Matemática não seja vista apenas como uma matéria relacionada a cálculos de valores numéricos e sim, como uma ciência que tem, como qualquer outra ciência, uma importância fundamental na vida das pessoas, que contribui de forma incontestável ao avanço da humanidade.

A Matemática não é algo que diz respeito a números, mas sim à vida. Ela é algo que nasce do mundo em que vivemos. Lida com ideias. E, longe de ser aborrecida e estéril, como muitas vezes é retratada, ela é cheia de criatividade. (Delvin, 2005, p.98) 


\section{Referências Bibliográficas}

[1] ANTON, Howard., Cálculo/Howard Anton, Irl Bivens, Stephen Davis; tradução Clauss Ivo Doering. Porto Alegre: Bookman,2007.

[2] ÁVILA, Geraldo Severo de Sousa., Cálculo 2: Funçôes de uma variável. Rio de Janeiro, RJ: Editora Rio de Janeiro: LTC - Livros Técnicos e Científicos Editora S.A., 1983.

[3] BOYER, C.B., História da Matemática; tradução Elza F. Gomide. São Paulo: Editora Edgard Blucher,1974.

[4] CARAÇA, Bento de Jesus., Conceitos Fundamentais da Matemática. Lisboa: Editora Fotogravura Nacional, 1970

[5] EVES, Howard., Introdução à História da Matemática. Campinas, SP: Editora da UNICAMP, 1997.

[6] IEZZI, Gelson, Fundamentos da matemática elementar, 7: geometria analítica; São Paulo, SP: Editora Atual, 2005.

[7] LEITHOLD, Louis., O cálculo com Geometria Analítica; tradução Cyro de Carvalho Patarra. São Paulo, SP: Editora Harbra, 2002.

[8] SIMMONS, George F., Cálculo com geometria analítica; tradução Seiji Hariki. São Paulo, SP: McGraw-Hill, 1987.

[9] GASPAR, Antônio Simões., Dissertação: As Cônicas, Quadráticas e suas Aplicações. Brasília, DF: UnB, 2014.

[10] CARNEIRO, José Paulo., A sombra do meu abajur. São Paulo, SP: RPM: Revista do Professor de Matemática No 59, 2012. 
[11] PEREIRA, Lúcia Resende; BONFIM, Valdir., Instrumentos articulados que desenham cônicas. São Paulo, SP: RPM: Revista do Professor de Matemática $\mathrm{N}^{\circ} 80$, 2006 .

[12] Disponível em: http://www.ufrgs.br/espmat/disciplinas/geotri/modulo4/ complementos/telescópios,hiperboles1.pdf, acessado em março de 2015. 